\title{
Comparative phylogeography of diadromous and freshwater daces of the genus Tribolodon (Cyprinidae)
}

\section{$\operatorname{AUTHOR}(\mathrm{S}):$}

Watanabe, Katsutoshi; Sakai, Harumi; Sanada, Takeshi; Nishida, Mutsumi

\section{CITATION:}

Watanabe, Katsutoshi ... [et al]. Comparative phylogeography of diadromous and freshwater daces of the genus Tribolodon (Cyprinidae). Ichthyological Research 2018, 65: 383-397

\section{ISSUE DATE:}

2018-07

URL:

http://hdl.handle.net/2433/250233

\section{RIGHT:}

This is a post-peer-review, pre-copyedit version of an article published in Ichthyological Research. The final authenticated version is available online at: http://dx.doi.org/10.1007/s10228-018-0624-9.; This is not the published version. Please cite only the published version.; この論文は出版社版でありません。引用の際には出版社版をご磪認じ 利用ください。 


\section{Comparative phylogeography of diadromous and freshwater daces of the genus}

\section{Tribolodon (Cyprinidae)}

\section{Katsutoshi Watanabe $^{1} \cdot$ Harumi Sakai $^{2} \cdot$ Takeshi Sanada $^{3,5} \cdot$ Mutsumi Nishida $^{4}$}

\section{Katsutoshi Watanabe}

watanak@terra.zool.kyoto-u.ac.jp

${ }^{1}$ Department of Zoology, Division of Biological Sciences, Graduate School of Science, Kyoto University, Kitashirakawa-Oiwakecho, Sakyo-ku, Kyoto 606-8502, Japan

${ }^{2}$ Department of Applied Aquabiology, National Fisheries University, 2-7-1 Nagata-Honmachi, Shimonoseki, Yamaguchi 759-6595, Japan

${ }^{3}$ Department of Marine Bioscience, Fukui Prefectural University, Gakuen-cho 1-1, Obama, Fukui 917-0003, Japan

${ }^{4}$ University of the Ryukyus, 1 Senbaru, Nishihara-cho, Okinawa 903-0213, Japan

${ }^{5}$ Present Address: Fukami Elementary School, Fukamidai, Yamato, Kanagawa 242-0013, Japan

Suggested running head: Comparative phylogeography of Tribolodon

Type of paper: full paper

Number of text pages: 27; Number of figures: 8 ; Number of tables: 1; Number of ESM: 4 (3 Figs. and 1 Table) 


\section{Abstract}

Far Eastern daces, genus Tribolodon (Cyprinidae), are thought to have diversified and developed unique diadromous life histories under changing conditions in the Sea of Japan and the surrounding environment. To examine the relationships between life history traits, distribution, and genetic population structures, we conducted a comparative phylogeographic analysis using partial mtDNA sequence data from samples collected over almost the full ranges of all four Tribolodon species. Phylogenetic analyses revealed several intraspecific haplotype groups that differentiated in the early Pleistocene to the Pliocene with or without geographic overlaps. A time-calibrated phylogeny suggested that the relatively smaller geographic ranges of the strictly freshwater species, T. sachalinensis and T. nakamurai, were explained not by the recent origins of these species, but by their limited dispersal abilities and smaller historical population sizes. The wider-ranging diadromous species, T. brandtii and $T$. hakonensis, exhibited similar major phylogeographic structures in their distributions, but the chronological order and timing of formation of this structure largely differed between the two species. In addition to those differences, the overlapping patterns of the differentiated intraspecific lineages in these species suggest dynamic, but somewhat restricted dispersal during the Plio-Pleistocene. Tribolodon hakonensis, one of the most widespread species of East Asian freshwater fishes, included both common and unique phylogeographic patterns compared to other fish species; the unique patterns (i.e., its wide range across freshwater biogeographic boundaries like the sea and mountains) would reflect its ecological features as a remarkable generalist inhabiting lakes, upper and lower reaches of rivers, and even coastal areas.

Keywords Freshwater fish $\cdot$ Mitochondrial DNA (mtDNA) $\cdot$ Far East Asia $\cdot$ Central Highland - Diadromy 


\section{Introduction}

The composition and regional heterogeneity of biological communities are determined through range expansion, geographical differentiation, and local extinction of component species (e.g., MacDonald 2003; Emerson and Gillespie 2008). These distribution processes are linked to the geological and climatic history of the regions where the communities occur. The processes are affected by both extrinsic factors (such as barriers or filtering, either by physiochemical environments or biological interactions) and intrinsic factors (e.g., ecological and life history traits, such as dispersal ability). Among the distribution processes, range expansion is the primary biogeographical process by which new species can become potential members of a community. The extent of range expansion would reflect a species' dispersal ability, as well as the length of time over which the species has dispersed. Intraspecific population structure, or phylogeographic information, is crucial for inferring historical range expansion (Avise 2000; Templeton 2006). Comparing phylogeographic patterns among component species with various ecological traits can deepen our understanding of the basic framework of community assembly processes on a regional scale.

Freshwater fish are a suitable group for studying the relationships between geological/climatic changes and the distribution of organisms, because the dispersal ability of these species is fundamentally restricted to freshwater systems that have been affected by such changes (Avise et al. 1987; Watanabe et al. 2016). This group includes strictly freshwater species (which are intolerant to salt water), diadromous species (which migrate between freshwater and marine environments), and peripheral freshwater species (which include brackish and sporadic freshwater fish) (see Myers 1949; Berra 2001). Different life history modes and their evolution can affect the distribution range and population structures of freshwater species groups. Specifically, the ranges of diadromous and peripheral species are likely to expand more quickly than those of strictly freshwater species, because the former groups could potentially disperse through the sea. Such dispersal often facilitates greater gene 
flow among local populations, which in turn inhibits population differentiation (Avise 2000; McDowall 2001, 2008). On the other hand, diadromous species often give rise to landlocked, regionally isolated populations and even species (e.g., chars, sticklebacks; Yamamoto et al. 2004; Takahashi et al. 2016). The relative importance of these two aspects may depend on specific features of migratory ecology (e.g., life history phase and timing of migration) as well as geological and climatic conditions. Comparisons of phylogeoraphic patterns among closely related species with different life history modes may help to clarify the relationships between ecological traits and distribution patterns, by eliminating extraneous factors due to phylogenetic constraints.

The Far Eastern dace genus Tribolodon is a unique group within the large family Cyprinidae, encompassing a variety of life histories, including fluvial (freshwater residential), lacustrine (migratory between river and lake), and diadromous (anadromous or amphidromous; sea run) modes (Nakamura 1969). The variability of life histories in Tribolodon makes it a good group for examining the relationship between distribution processes and ecological differences. This genus consists of four species, distributed around the Sea of Japan, and its evolution is likely to have been shaped by the formation of the Sea of Japan since the Miocene (Nishimura 1974; Sakai 1995; Sakai et al. 2002; Imoto et al. 2013). The genus includes two diadromous species (Tribolodon brandtii and T. hakonensis) and two freshwater resident species (T. nakamurai and T. sachalinensis), whose geographic range sizes are various (Fig. 1; see "Materials and methods" for more details). The four species are morphologically similar to each other, and interspecific hybrids frequently occur in sympatric areas (Sakai and Hamada 1985; Sakai 1995; Atsumi et al. 2017). Because of these features, Tribolodon species have attracted considerable attention in ecological, physiological, and evolutionary contexts, particularly in connection with the geological history of the Sea of Japan (e.g., Sakai 1995; Kaneko et al. 1999; Sakai et al. 2002). The speciation and distribution patterns of these species, along with related phoxinin groups, have been repeatedly examined using allozyme and mitochondrial DNA (mtDNA) data (Sakai et al. 2002, 2006; Sasaki et al. 
2007; Ryazanova and Polyakova 2012; Brykov et al. 2013; Imoto et al. 2013). However, to date, no studies have compared the detailed phylogeographic patterns of these species with full geographic sampling using high-resolution genetic markers.

In this study, we analyzed the phylogeographic patterns of all four Tribolodon species using mtDNA sequence data from samples collected over almost the full ranges of these species. Comparing patterns among these four species in a common spatiotemporal framework, we explored the following questions: whether the wideness of each of their ranges is attributable to life history modes or the timing of the origin of the species; whether some Tribolodon species show common phylogeographic patterns; and, if so, whether these patterns were formed on the same timescale. Finally, we discuss the evolutionary and distribution history of Tribolodon species compared to those of other freshwater fishes distributed around the Sea of Japan.

\section{Materials and methods}

Background of study area and species. The four Tribolodon species are distributed around the Sea of Japan, including the Japanese Archipelago, Sakhalin Island, the southern Kuril Islands, the Russian Maritime Territory (Primorsky Region), and the Korean Peninsula (Fig. 1). The Sea of Japan began to open at the eastern margin of the Eurasian continent in the Early Miocene (Tada 1994; Yonekura et al. 2001). The sea has subsequently experienced drastic environmental fluctuations, including changes in temperature, salinity, and oxygen concentration, due to periodic closing of the southern channel of the sea, blocking the inflow of the Tsushima Current from the southwest (e.g., Jolivet et al. 1994; Tada 1994; Kitamura and Kimoto 2006). The Japanese Archipelago is the center of distribution of Tribolodon; all four species of the genus can be found in this area. Strictly freshwater fish native to the Japanese Archipelago show primary differences across the boundaries of the Ishikari Plain in 
western Hokkaido and the Fossa Magna region (Central Highlands area) in central Honshu (Fig. 2; e.g., Watanabe 2012; Watanabe et al. 2016).

The genus Tribolodon (Far Eastern dace, or red fin) belongs to subfamily Leuciscinae in the family Cyprinidae. Tribolodon is closely related to the genus Pseudaspius, whose sole species, Pseudaspius leptocephalus, occurs in the basins of the Amur River, Sakhalin Island, and Mongolia (Sakai et al. 2002; Sasaki et al. 2007; Imoto et al. 2013). Some studies have suggested that Tribolodon is paraphyletic, with a closer relationship between P. leptocephalus and one or more species of Tribolodon than between Tribolodon species (Sasaki et al. 2007; Imoto et al. 2013). The Tribolodon-Pseudaspius clade is included in the Far Eastern phoxinin group together with Rhynchocypris (the Far Eastern "Phoxinus"; Sakai et al. 2006; Imoto et al. 2013).

One of the four valid species of the genus, Tribolodon hakonensis (Japanese common name, "Ugui"), exhibits intraspecific variation in life history, including fluvial, lacustrine, and sea-run types. This species occurs in rivers, lakes, and river mouths to coastal areas throughout the range of the genus, and possesses high osmoregulatory capability (Fig. 1; Sakai 1995). It is one of the most widespread freshwater fish species in East Asia. The distributions of the other three species, however, are relatively restricted to the northern parts of the range of the genus (Fig. 1). Tribolodon brandtii has an anadromous lifestyle, and includes two subspecies: Tribolodon brandtii brandtii (“Jusan-ugui”) and Tribolodon brandtii maruta ("Maruta") (Sakai and Amano 2014). The remaining two species, Tribolodon sachalinensis ("Ezougui”) and Tribolodon nakamurai ("Ukekuchi-ugui”), are freshwater residents (Sakai 1995; Sakai and Imai 2002; Imai et al. 2008). Some authors recognize a fifth species, Tribolodon sp., from the Primorsky region (e.g., Semina et al. 2006; Brykov et al. 2013), which probably corresponds to one of the regional groups of T. hakonensis in the present paper (see "Discussion”).

Specimens. In total, 400 specimens of the four Tribolodon species were collected from 49 river systems in Japan (locality code 1-43), Sakhalin (44-45) and Primorsky (46-47) in 
Russia, and the Korean Peninsula (48-49) between 1991 and 2016 (Fig. 2; Table 1). Because of the small number of specimens of T. nakamurai $(n=3)$, our analyses included four additional T. nakamurai sequences retrieved from a DNA database (AB198967, 198968, Sasaki et al. 2007; AB218896, Saitoh et al. 2006; KP219892, N. Polyakova, unpublished data). Specimens with suspected introgressed mtDNA, i.e., those possessing mtDNA of a different species from that inferred from a previous allozyme analysis (Sakai et al. 2002), were not included in the present study. A specimen of Pseudaspius leptocephalus from the Chita River (Amur River system, Chita, Russia) was also included in the analyses because of its close relationship to Tribolodon (Sakai et al. 2002; Sasaki et al. 2007; Imoto et al. 2013). An additional sequence (AP009058; Saitoh et al. 2006) from this species was also used. Four phoxinin species were used as outgroups: sequences were obtained from one specimen each of Rhynchocypris lagowskii steindachneri and Rhynchocypris oxycephalus, collected from the Ishida River, Lake Biwa system, Shiga, central Honshu, Japan, and previously published sequences for Rhynchocypris percnurus (AP009150; Imoto et al. 2013) and Oreoleuciscus potanini (AB626851; Imoto et al. 2013) were also included.

DNA sequencing. Total genomic DNA was isolated from a piece of fin or muscle preserved in $99 \%$ ethanol using a standard phenol/chloroform method or Genomic DNA Purification kit (Promega, Tokyo, Japan). Polymerase chain reaction (PCR) amplification was carried out using the primer pair L14724 (5'- TGA CTT GAA RAA CCA YCG YYG -3') (Palumbi et al. 1991) and H15915 (5'- ACC TCC GAT CTY CGG ATT ACA AGA C -3') (Aoyama et al. 2000) to amplify the mtDNA cytochrome $b$ gene region (cyt $b$ ) for all specimens. PCR conditions consisted of 30 cycles of denaturation $\left(94{ }^{\circ} \mathrm{C}\right.$ for $\left.15 \mathrm{~s}\right)$, annealing ( $48^{\circ} \mathrm{C}$ for $15 \mathrm{~s}$ ), and extension $\left(72{ }^{\circ} \mathrm{C}\right.$ for $60 \mathrm{~s}$ ) on a thermal cycler (ASTEC, Fukuoka, Japan). Then, PCR products were purified with ExoSAP-IT (USB Corp., Cleveland, OH) or Illustra ExoStar (GE Healthcare Japan, Tokyo, Japan) at $37{ }^{\circ} \mathrm{C}$, and sequenced on an automated DNA sequencer (GA3130xl; Applied Biosystems, Foster City, CA) with primer H15915 to obtain the 3'-half sequences of cytb (758 bp; hereafter, “short sequences"), using a BigDye 
Terminator Cycle sequencing FS Ready Reaction kit ver. 3.1 (Applied Biosystems). We obtained longer sequences $(2,941 \mathrm{bp}$; “long sequences") of selected samples $(n=39)$ with haplotypes representing each major clade, as detected in the analysis of the short sequences. These long sequences included parts of the cytb $(1,084 \mathrm{bp})$, cytochrome $c$ oxidase subunit I (COI; $655 \mathrm{bp}$ ), and 16S ribosomal RNA (16S; 1,202 bp) regions, and allowed us to construct a more credible phylogeny. We used the following primers: FishCO1F (5'- TCA ACC AAC CAC AAA GAC ATT GGC AC -3') and FishCO1R (5'- TAG ACT TCT GGG TGG CCA AAG AAT CA $-3^{\prime}$ ) for COI (annealing $52^{\circ} \mathrm{C}$ ) (Ward et al. 2005), and L1854 (5'-AAA CCT CGT ACC TTT TGC AT -3'; Watanabe et al. 2000) and H3058 (5'- TCC GGT CTG AAC TCA GAT CAC GTA -3'; Kitaura et al. 1998) for $16 \mathrm{~S}$ (annealing $52{ }^{\circ} \mathrm{C}$ ). The resulting sequences were deposited in the DNA databank DDBJ/EMBL/GenBank (accession numbers LC277189-LC277704). The haplotype frequencies of each population were deposited in the Genetic Diversity and Distribution Map (GEDIMAP) freshwater fish database (http:// gedimap.zool.kyoto-u.ac.jp; Watanabe et al. 2010) with population IDs P2201-2260.

Phylogenetic and phylogeographic analyses. DNA sequences were edited and aligned with ClustalW and by eye using MEGA 7.0 (Kumar et al. 2016). Phylogenetic analyses were conducted on both datasets (short and long sequences) using maximum likelihood (ML) and Bayesian inference (BI) methods. The ML tree and 1,000 non-parametric bootstrap replicates (ML BP) were obtained under the GTRCAT model (partitioning by gene in the long-sequence dataset) implemented in RAxML ver. 8.0 (Stamatakis 2014).

In BI analyses, we estimated the time-calibrated tree based on the long sequence data with the prior assumptions for molecular substitution rate and date of the geological barrier for population isolation, calculated according to the relaxed molecular clock model (Drummond et al. 2006). Substitution and clock model parameters were estimated separately for each of the three genes. We used molecular substitution rates estimated for teleost cyt $b$, ranging from roughly $0.3 \%$ to $1.5 \%$ per million years (Myr) per lineage (e.g., Burridge et al. 2008; Watanabe and Takahashi 2010) with a mean of 0.76 \% (for European cyprinids; 
Zardoya and Doadrio 1999). We adopted the uncorrelated lognormal relaxed clock model with a normal prior distribution for mean molecular substitution rate, giving $0.76 \%(\mathrm{SD}=$ $0.5 \%$ ) for cyt $b$; this is a lax constraint, covering $<0.3-1.6 \%$ in a $95 \%$ interval. The mean substitution rates of the other two genes (COI and $16 \mathrm{~S})$ were estimated using the CTMC rate reference prior (Ferreira and Suchard 2008). The uplift of the Suzuka Mountains in central Honshu Island 1.0-1.5 million years ago (Mya) (Fig. 2; Yokoyama 1988; Kawabe 1994) was hypothesized to have worked for the relevant divergence and used for the corresponding node age in T. hakonensis as a geological constraint (see "Results"). This constraint was specified as a lognormal prior distribution, ranging from approximately 1.1 to $1.5 \mathrm{Mya}$ in the $95 \%$ range $[$ mean $=1.3 \mathrm{Mya} ; \log (\mathrm{SD})=0.1$; offset $=0]$. To examine the concordance between molecular substitution rates and geological constraints, we also constructed a time tree using only the calibration by molecular substitution rate as a more lax constraint.

The Bayesian phylogenetic tree and divergence time (the time of the most recent common ancestor; tMRCA) were estimated using the above assumptions and a Yule (speciation) tree prior with BEAST 1.8.4 (Drummond and Rambaut 2007). The substitution models were selected using the Bayesian information criterion (BIC) in jModelTest 2.1.6 (number of substitution schemes $=5$; Darriba et al. 2012): $\mathrm{TrN}+\mathrm{G}$ for cyt $b$ and COI and $\mathrm{HKY}+\mathrm{G}+\mathrm{I}$ for $16 \mathrm{~S}$. All other model parameters were set to the default priors. For MCMC analyses, we performed two independent runs of 50 million generations to confirm the consistency of the results. We sampled every 2,000 generations and removed the first $10 \%$ of samples as burn-in. The convergence of the chains to the stationary distribution and large effective sample size (>200) were confirmed using Tracer v.1.6 (Rambaut et al. 2013). The consensus tree with median node heights was calculated by TreeAnnotator v.1.8.4 in the BEAST package, and the tree was visualized using FigTree v.1.4.3 (Rambaut 2016). Node support was evaluated based on posterior probability (BI PP).

A statistical parsimony network for each species was constructed using TCS v1.2.1 (Clement et al. 2000) at a $95 \%$ confidence limit for the mtDNA haplotypes obtained. Loops 
were resolved so that the topology becomes consistent with that of the ML tree. The grouping of haplotypes followed the nesting rule by Templeton and Sing (1993).

\section{Results}

Major divergences and their timing. The phylogenetic tree based on the "short sequences" supported the monophyly of each species and subspecies of Tribolodon with high bootstrap values (89-100\%), with the exception of T. brandtii, whose monophyly was not supported (Fig. 3). The monophyly of T. brandtii + T. nakamurai + T. sachalinensis + Pseudaspius leptocephalus was also supported with a high bootstrap value (94\%), but this result was less well supported in ML and BI trees based on the "long sequences" [ML BP $=77 \%, \mathrm{BI} P \mathrm{PP}=$ 0.84; Fig. 4, Electronic supplementary material (ESM) Fig. S1].

In the time-calibrated tree based on the long sequences with the prior assumptions for the cytb substitution rate and the date of the Suzuka Mountains vicariance (see below), the mean evolutionary rates (nucleotide substitutions per million years per lineage) of the respective genes were estimated at a median of $0.79 \%$ [95 \% highest probability density (HPD), $0.58-1.1 \%$ ] for cyt $b, 0.48 \%(0.32-0.67 \%)$ for COI, and $0.22 \%(0.15-0.31 \%)$ for $16 \mathrm{~S}$, and no remarkable changes appeared over the tree. When only the molecular substitution rate was used, without the Suzuka Mountains vicariance calibration, similar, slightly faster evolutionary rates $(1.02 \%$ for cyt $b, 0.62 \%$ for COI, and $0.29 \%$ for $16 \mathrm{~S})$ were obtained. The time of isolation by the Suzuka Mountains was consequently estimated to be slightly more recent than that with the geological constraint [1.26 (1.03-1.52) vs. $0.96(0.35-2.53)$ Myr; see below], but the $95 \%$ HPDs were completely overlapped. We thus concluded that there was no remarkable discrepancy between the evolutionary rate and geological constraints assumed in our analyses.

In the time-calibrated tree, the median tMRCA of Tribolodon and Pseudaspius species 
(node 1 in Fig. 4) was estimated to be 8.66 Myr (95 \% HPD, 5.83-11.79). Interspecific relationships in this tree were not well resolved, except for the close relationship between $T$. brandtii and T. nakamurai. However, the time tree and haplotype networks revealed clear intraspecific groups of Tribolodon species, associated with geographical distribution.

\section{Phylogeography of T. brandtii, T. nakamurai, and T. sachalinensis. Tribolodon}

brandtii was clearly divided into two haplotype groups (ML BP $=100 \%, \mathrm{BI}$ PP $=1.0$ for both) with an average sequence difference of $3.9 \%( \pm 0.2 \mathrm{SD})$ in the short sequences (ESM Table S1). These groups correspond to the subspecies T. brandtii brandtii and T. brandtii maruta (TBB and TBM; Figs. 4, 5), which are distributed around the Sea of Japan and on the Pacific side of eastern Honshu, respectively (Fig. 5). The tMRCA between these two subspecies was estimated at 3.04 Myr (95\% HPD, 2.00-4.29 Myr), which was the greatest amount of intraspecific divergence among Tribolodon species (node 3 in Fig. 4). Tribolodon brandtii brandtii was further separated into two haplotype groups (TBB1 and TBB2) with an average sequence difference of $1.6 \%( \pm 0.2 \mathrm{SD})$. These groups were distributed in the northern (northwestern Honshu, Hokkaido, and Sakhalin) and southwestern parts (Korea and southern Primorsky) around the Sea of Japan, respectively (Fig. 5). The boundary of these two groups was probably located in central to northern Primorsky, but due to insufficient sampling, its location was not clear. The divergence time between the two groups was estimated at 0.95 Myr (0.52-1.47 Myr; node 4). Both groups include widespread haplotypes such as bb06 and 08 (TBB1; locality code 14-Shinano River to 44-Sakhalin) and bb10 and 11 (TBB2; 47-Peter the Great Bay to 49-Korea) (Table 1).

Tribolodon nakamurai formed a monophyletic group with T. brandtii; the tMRCA of the two species was estimated at 3.29 Myr (2.17-4.62 Myr; node 2 in Fig. 4). Three haplotypes (n01-03) were identified. No geographical structure was found in the distribution of this species, although the sample size was too small to detect it, if present (Fig. 6; Table 1).

The estimated tMRCA of Tribolodon sachalinensis was 0.66 Myr (0.36-1.07 Myr; node 5 in Fig. 4), and there were no clear genetic divisions within the species. However, some 
haplotypes, such as sa10 and 17, showed differentiation from major haplotypes (Fig. 7).

Phylogeography of T. hakonensis. Tribolodon hakonensis showed high intraspecific diversity, including six mtDNA haplotype groups (TH1-TH6) with a tMRCA of 2.61 Myr (1.72-3.59 Myr; node 6 in Fig. 4). The distributions of these groups partially overlapped (Fig. 8). The group TH6 was the first to be derived ( $\mathrm{ML} \mathrm{BP}=95 \% ; \mathrm{BI} P P=1.0$ ) and was distinct from the other groups (TH1-TH5) in a statistical parsimony network at $95 \%$ or even $90 \%$ confidence limits. The average sequence difference between TH6 and TH1-TH5 haplotypes was $3.2 \%$ ( $\pm 0.3 \mathrm{SD})$. Similar to TBB2 of T. b. brandtii, TH6 was found in the southwestern surroundings of the Sea of Japan (Korea and southern Primorsky); however, a subgroup (TH6-2, the derived group as inferred from root position) extended into Tsushima Island and the northern part of Kyushu, Japan (loc. codes 43 and 40; Figs. 2, 8d). The divergence time between TH6-1 (continental) and TH6-2 (Japan) was estimated at 0.54 Myr (0.25-0.89 Myr; node 11 in Fig. 4).

The Suzuka Mountains separated the range of the group TH5 from the ranges of the other northeastern groups (TH1-TH4) (Fig. 8). Although the phylogenetic relationships among groups TH1-TH5 were not fully resolved, the sister relationship of TH5 and TH3 + TH4 was supported by a moderately high bootstrap value in the ML analysis ( $80 \%$; Fig. 4; ESM Fig. S1). Hence, the timing of uplift of the Suzuka Mountains was used to calibrate the tree (node 8 in Fig. 4; see "Materials and methods"), giving a tMRCA of 1.26 (1.03-1.52) Myr for TH5 + (TH3 + TH4). Diversification of TH1-TH5 was inferred to have started 1.30 (1.03-1.62) Mya (node 7 in Fig. 4).

TH1 was restricted to the northern part of the range of T. hakonensis, i.e., the Tumnin River (Khabarovsk), Sakhalin, and Hokkaido (Fig. 8a). TH2 was distributed on the Pacific side of eastern Honshu (Fig. 8a), with a range similar to that of T. b. maruta (TBM). TH3 was a major group in the middle to northern parts of the range (Fig. 8b), overlapping with the range of TH1 and part of the range of TH2. TH3 consisted of some major widespread haplotypes (e.g., h37 and h47; Table 1) with several close haplotypes. 
TH4 was mainly distributed on the Pacific side of central Honshu, but was also found in the rivers flowing into the Sea of Japan in midto northern Honshu, across the Fossa Magna region (Figs. 2, 8c). The haplotypes in the latter area (TH4-2) were differentiated from those on the Pacific side (TH4-1), but these subgroups were sympatric in the intermediate mountainous locations (loc. codes 24, 26). The tip position of TH4-2 in the haplotype network suggested the dispersal direction from the Pacific side to the Sea of Japan side (Fig. 8c). The divergence time between TH4-1 and TH4-2 was estimated at 0.43 Myr (0.25-0.65 Myr; node 9 in Fig. 4).

TH5 was the most diverse group. It was distributed in western Japan with a tMRCA of 0.56 Myr (0.34-0.80 Myr; node 10 in Fig. 4; Fig. 8d). Haplotypes h10-h12 were in a basal position in the haplotype network of this group (Fig. 8d, e; Table 1) and were only found in samples from the Lake Biwa system. In the Lake Biwa system, haplotypes of another subgroup (h33-35) were also found. TH5 contained at least five subgroups, which to some extent corresponded with the geographical distribution (Table 1; ESM Fig. S2).

Comparisons of diversification patterns and timing. The two diadromous Tribolodon species, T. brandtii and T. hakonensis, have wider ranges than the two freshwater species (Fig. 1), and estimates of their tMRCAs were similar (ca. 3 Myr; Fig. 4). The divergence times of the two freshwater species, T. nakamurai and T. sachalinensis, were not necessarily shorter than those of the diadromous species, but the freshwater species had shorter tMRCAs, equivalent to those of regional haplotype groups of the diadromous species (Figs. 3, 4). The two diadromous species showed similar phylogeographic patterns. That is, in both $T$. brandtii and T. hakonensis, distinct regional haplotype groups were found in the southwestern side of the Sea of Japan (Korea to Peter the Great Bay; TBB2 and TH6) and the Pacific side of eastern Honshu (TBM and TH2; Figs. 5, 8). However, the chronological order and timing of haplotype group divergence differed between the two species. In T. brandtii, the primary divergence (node 3 in Fig. 4) was between populations on the Pacific side (TBM) and the Sea of Japan side (TBB) (divergence time: 2.00-4.29 Myr of 95 \% HPD, as mentioned above); 
these two groups corresponded to the two different subspecies T. b. maruta and T. b. brandtii (see Sakai and Amano 2014). The second divergence occurred around the Primorsky region in this species (divergence time: 0.52-1.47 Myr; node 4 in Fig. 4). By contrast, the vicariance around the Primorsky region represents the primary divergence of T. hakonensis, with an estimated divergence time of 1.72-3.59 Myr (node 6 in Fig. 4). The haplotype group of $T$. hakonensis distributed in the Pacific side of Honshu (TH2) diverged more recently, around one million years ago (Fig. 4), and is partially sympatric with the TH3 group (Fig. 8).

The range of the TH3 haplotype group of T. hakonensis was similar to the range of $T$. sachalinensis, but the tMRCA was shorter in the former [0.23 (0.09-0.43) Myr for TH3 of $T$. hakonensis and 0.66 (0.36-1.07) Myr for T. sachalinensis; Fig. 4]. Tribolodon sachalinensis had a tMRCA rather similar to that of the clade TH3 + TH4 [0.71 (0.46-1.02) Myr].

\section{Discussion}

Comparative phylogeography of Tribolodon fishes. Our time-calibrated mtDNA gene tree suggested that the wideness of a species' range depends more on life history modes than on the timing of the origin of the species. That is, the freshwater species (Tribolodon nakamurai and Tribolodon sachalinensis) are distributed over narrower ranges than the diadromous species (Tribolodon brandtii and Tribolodon hakonensis), although the former did not necessarily originate more recently. This conclusion, however, should be confirmed by information from nuclear genes, because it is based on the assumption that the mtDNA tree properly reflects the species history.

On the other hand, the tMRCAs were shorter in the freshwater species, suggesting their smaller historical population size compared with the diadromous species (e.g., Avise 2000). The implication is that geographic range and historical population size in Tribolodon species reflect their ecological features, particularly migration and range of tolerance for salinity and 
temperature. Diadromy enabled by high osmoregulatory capability would have made it easier for the diadromous species to migrate to refugia and re-expand their range (McDowall 2001). Specifically, the variable life history mode and wide habitat tolerance (lower to upper reaches of rivers, lakes, and coastal areas) of T. hakonensis are likely to have played an important role in forming its remarkably wide distribution.

The two diadromous species, T. brandtii and T. hakonensis, had similar major phylogeographic structures, but their chronological order and timing of formation differed between these species. This indicates that their apparently similar phylogeographic patterns resulted from dispersal and isolation in different periods. The common patterns between the two species, i.e., the vicariance across the Primorsky region and the isolation of populations on the Pacific side of eastern Honshu, are partially supported by previous studies (Sakai et al. 2002; Sasaki et al. 2007), particularly those with large number of specimens from the Russian region (e.g., Brykov et al. 2011, 2013). The obvious geographic structure of these populations suggests that stepping-stone dispersal along the coast is not necessarily easy even for diadromous species; it is probably inhibited by long distances between river mouths, coastal topography, and the direction and intensity of ocean currents. Repeated opportunities for dispersal and isolation caused by environmental fluctuations around the Sea of Japan during the Plio-Pleistocene climatic oscillations (Tada 1994; Kitamura and Kimoto 2006) could have formed similar geographic patterns observed here in historically different ways.

Brykov et al. (2013) suggested that species in the Russian regions followed a common intraspecific divergence pattern; this assertion is partially supported by our results, which are based on wider geographic sampling. On the basis of mtDNA RFLP data, Brykov et al. (2013) found two or three mtDNA lineages that occur partially or largely sympatrically from Peter the Great Bay to Sakhalin Island in T. brandtii brandtii, T. sachalinensis, and T. hakonensis (excluding our TH6) (ESM Fig. S3). They estimated the intraspecific divergence (pairwise sequence difference) for these three species at $2.3 \%, 2.9 \%$, and $2.1 \%$, respectively, and claimed that the intraspecific lineages diverged as a result of common historical factors for 
isolation and secondary contact. Although it is difficult to directly compare our sequence data with their RFLP data, the distribution patterns and degrees of divergence suggest that our TBB1 and TBB2 of T. $b$. brandtii correspond to phylogroups 3 and 2 of Brykov et al. (2013). Haplotype sa17 and others probably correspond to their phylogroups 2 and 1 of $T$. sachalinensis, and TH1 and TH3 correspond to phylogroups 1 and 2 (or vice versa) of $T$. hakonensis. The pairwise uncorrected p-distances of our cyt $b$ data were $1.61 \%$ for the TBB1 and TBB2 groups of T. b. brandtii, $1.03 \%$ for Haplotype sa17 and other T. sachalinensis sequences, and $1.64 \%$ for the TH1 and TH3 groups of T. hakonensis (ESM Table S1). These values support the conclusions of Brykov et al. (2013), at least with regard to T. b. brandtii and T. hakonensis, although it is more difficult to draw conclusions about $T$. sachalinensis due to the small number of Russian specimens in the present study. Furthermore, Brykov et al. (2013) showed the existence of the third group (phylogroup 1) of T. b. brandtii, which was distributed mainly around Peter the Great Bay; we may not have analyzed any samples of this group. The range of this group extends to Sakhalin Island (haplotype C of Brykov et al. 2013). This pattern suggests that partial secondary contact occurred on that island, involving T. $b$. brandtii immigrants that crossed the Primorsky vicariance.

Phylogeography of Tribolodon hakonensis. As a species with a remarkably wide distribution, T. hakonensis shares several common phylogeographic patterns with other freshwater fishes in Japan and adjacent regions. For example, T. hakonensis in the Japanese Archipelago is largely divided by the Suzuka Mountains (haplotype group TH3-TH4 vs. TH5); this mountain range, which was uplifted about 1.0-1.5 Mya (Yokoyama 1988; Kawabe 1994), is an important biogeographic boundary dividing species and populations of many other freshwater fishes (Watanabe et al. 2016). In addition, T. hakonensis populations west of the mountains have maintained diverse haplotypes, and different mtDNA lineages co-occur in some localities, as typified by the population in Lake Biwa, an ancient lake (Table 1; ESM Fig. S2). This phylogeographic pattern is observed in several widespread species in western Japan (Tabata et al. 2016). 
The inferred penetration of the haplotype group TH6 from the continental regions (Primorsky to the Korean Peninsula) to Tsushima Island and even into a part of Kyushu Island in Japan (Fig. 8d) provides a good example of the colonization of western Japan by freshwater fish from the Korean Peninsula (Aoyagi 1957; Nishimura 1974; Mizuno 1987). This is also supported by allozyme data, which show that the continental allele $* 85$ at Prot- $2 *$ can be found in Tsushima Island populations (Sakai et al. 2002). Our results, however, do not support the hypothesis that such colonization by continental freshwater fish occurred in the last glacial period (0.01-0.07 Myr ago) (e.g., Lindberg 1972; Nishimura 1974). Instead, genetic differentiation within TH6 suggests that colonization of western Japan occurred in the middle Pleistocene (0.25-0.93 Myr ago), even in the case of diadromous species. In recent Russian references, the southwestern continental population, most likely the same as our TH6 group, is treated as "Tribolodon sp." (e.g., Semina et al. 2006; Brykov et al. 2011, 2013). In our data, the genetic differentiation between TH6 and TH1-TH5 (3.2\% uncorrected p-distance) is equivalent to that between the two subspecies of T. brandtii (3.9\%). Gudkov et al. (2010) reported morphological differences between southern Primorsky and Sakhalin populations. Further, Polyakova et al. (2015) stated the possibility that the southwestern continental population (Tribolodon sp.) was formed as a result of homoploid hybridization between $T$. hakonensis and T. brandtii, based on the data from four nuclear DNA loci. Inclusive morphological comparisons and genome-wide studies are necessary to determine the taxonomic and evolutionary status of the southwestern continental population of $T$. hakonensis.

Several aspects of the phylogeographic patterns of T. hakonensis are quite different from those of other freshwater fishes. Most strictly freshwater fish species are found only on one side of the Ishikari Plain in western Hokkaido; few fish species in western Japan occur north of the plain (Nishimura 1974; Watanabe 2012). The remarkably wide distribution of $T$. hakonensis across this boundary would be achieved by its diadromous, euryhaline, and eurythermal habits. On the other hand, multiple well-differentiated mtDNA haplotype groups 
(e.g., TH1 and TH3) co-occur in the northern part of this species' range. This suggests repeated reduction and reexpansion of its distribution, involving genetic isolation and secondary contact, probably influenced by the global climate oscillation in the Pleistocene. A similar overlapping pattern of mtDNA haplotype groups is observed in the white-spotted char, Salvelinus leucomaenis, which is also a euryhaline fish (Yamamoto et al. 2004).

Another noticeable pattern is the relatively recent $(0.24-0.64$ Mya, in the middle Pleistocene) penetration of TH4 from the Pacific side to the Sea of Japan side of Honshu Island, across the Central Highlands region (around the Fossa Magna). The Central Highlands region is the second most important boundary for freshwater fish in the Japanese Archipelago (Nishimura 1974; Watanabe 2012), and its uplift in the Plio-Pleistocene has caused deep differentiation in many fish groups at interand intraspecific levels (e.g., bitterlings, minnows, loaches, and catfishes; see Watanabe et al. 2016). The expansion of the range of T. hakonensis across this mountainous area may have been enabled by its ability to inhabit the upper reaches of rivers (e.g., Nakagawa 2014), providing more opportunities to expand their range via river captures across watersheds in mountainous areas (e.g., Kitagawa et al. 2001; Burridge et al. 2006). Finer-scale analyses with highly sensitive molecular markers for T. hakonensis will contribute to a deeper understanding of the relationship between ecology and distribution in freshwater fishes.

Evolutionary history of Tribolodon. Our analyses suggest that Tribolodon + Pseudaspius species diversified from the Late Miocene to the early Pleistocene, emphasizing the importance of the environmental changes in the Sea of Japan during those periods in the formation of diadromous freshwater fish fauna in this area. Some cold water-adapted euryhaline fishes, such as sticklebacks (Gasterosteus and Pungitius) and sculpins (Cottus), have also been inferred to have diversified around the Sea of Japan in those periods (Higuchi and Goto 1996; Yokoyama and Goto 2005; Kitano et al. 2007; Takahashi et al. 2016). The Sea of Japan opened from about 20 to 14 Mya (e.g., Jolivet et al. 1994; Tada 1994; Yonekura et al. 2001; Kitamura 2010), when the common ancestor of Tribolodon and Pseudaspius, or that of 
Far Eastern phoxinins, probably inhabited this area (Fig. 4). Salinity and temperature in the Sea of Japan fluctuated with climatic changes and the opening and closing of its southern strait (the Tsushima Strait) (e.g., Iijima and Tada 1990; Kitamura and Kimoto 2006). These conditions may have facilitated the diversification of freshwater fishes involving evolutionary changes associated with the diadromous lifestyle.

The phylogenetic relationships and divergence times of the Tribolodon + Pseudaspius species remain uncertain, although these elements are essential to reconstruct the evolution of diadromy in this group. Our results, based on partial mtDNA data, do not allow us to propose a strong phylogenetic hypothesis for Tribolodon + Pseudaspius species. However, the topology of our BI tree (Fig. 4) is identical to that produced by complete mitochondrial genome data (Imoto et al. 2013). This mtDNA relationship does not support the monophyly of diadromous Tribolodon species (i.e., T. brandtii and T. hakonensis). However, allozyme data support different tree topologies, i.e., with Pseudaspius leptocephalus positioned outside of Tribolodon (Kartavtsev et al. 2002; Sakai et al. 2002) and with the diadromous species, $T$. brandtii and T. hakonensis, being monophyletic (Sakai et al. 2002). Interspecific hybridization (Sakai and Hamada 1985; Sakai 1995) and allelic introgression (Sakai et al. 2002) have also been reported among Tribolodon species; these findings are supported by a small degree of interspecific mtDNA introgression found in our preliminary analyses (unpublished data). These aspects may introduce bias into the matrilineal genealogy for interspecific relationships.

Different studies have also introduced discrepancies among divergence times; our estimations were much smaller (e.g., about 6-12 Myr for tMRCA of Tribolodon + Pseudaspius) than those proposed by Imoto et al. (2013) (13-23 Myr, as measured from figure 5 of Imoto et al. 2013). This seems to be due to differences in the calibration data used for dating the tree. We used a geographic event and the molecular evolutionary rates obtained from cyprinids and other teleosts as time constraints. Although our two constraints were roughly concordant with each other, their applicability might need to be reexamined. On the 
other hand, the estimate of Imoto et al. (2013) should also be treated with caution, because their tree was calibrated with nodes 10 to a 100 times older (about 60-140 Myr). Different datasets from multiple nuclear genes and a more inclusive approach to time calibration are necessary to more accurately estimate divergence times in future research.

Acknowledgments We thank S. Amano, A. Goto, R. Kakioka, H. Kato, K. Katsura, H. Kohno, K. Iguchi, S.-R. Jeon, T. Kaneko, S. N. Safronov, H. Sugiyama, R. Tabata, Y. Takahashi, T. Tokuhara, V. V. Tsuiger, G. Yamamoto, Y. Yamazaki, and A. Zama for their help in the collection of specimens. This study was partially supported by the Sumitomo Foundation and JSPS KAKENHI (No. 06041004, 09041138, 21370035, 26291079, 26250044, and 17H03720).

\section{References}

Aoyagi H (1957) General notes on the freshwater fishes of the Japanese Archipelago. Taishukan, Tokyo

Aoyama J, Watanabe S, Ishikawa S, Nishida M, Tsukamoto K (2000) Are morphological characters distinctive enough to discriminate between two species of freshwater eels, Anguilla celebesensis and A. interioris? Ichthyol Res 47:157-161

Atsumi K, Nomoto K, Machida Y, Ichimura M, Koizumi I (2017) No reduction of hatching rates among F1 hybrids of naturally hybridizing three Far Eastern daces, genus Tribolodon (Cypriniformes, Cyprinidae). Ichthyol Res. https://doi.org/10.1007/s1022 8-017-0588-1

Avise JC (2000) Phylogeography: the history and formation of species. Harvard University Press, Cambridge 
Avise JC, Arnold J, Ball RM Jr, Bermingham E, Lamb T, Neigel JE, Reeb CA, Saunders NC (1987) Interspecific phylogeography: the mitochondrial DNA bridge between population genetics and systematics. Annu Rev Ecol Syst 18:489-522

Berra TM (2001) Freshwater fish distribution. Academic Press, San Diego

Brykov VA, Polyakova NE, Semina AV (2011) Phylogeographic analysis reveals two periods of divergence in large scaled redfin Tribolodon hakonensis (Pisces, Cyprinidae). Russ J Genet 47:1324-1332

Brykov VA, Polyakova NE, Semina AV (2013) Comparative analysis of mitochondrial DNA variation in four species of Far Eastern redfins of the genus Tribolodon (Pisces, Cyprinidae). Russ J Genet 49:310-319

Burridge CP, Craw D, Waters JM (2006) River capture, range expansion, and cladogenesis: the genetic signature of freshwater vicariance. Evolution 60:1038-1049

Burridge CP, Craw D, Fletcher D, Waters JM (2008) Geological dates and molecular rates: fish DNA sheds light on time dependency.Mol Biol Evol 25:624-633

Clement M, Posada D, Crandall KA (2000) TCS: a computer program to estimate gene genealogies. Mol Ecol 9:1657-1660

Darriba D, Taboada GL, Doallo R, Posada D (2012) jModelTest 2: more models, new heuristics and parallel computing. Nat Methods 9:772

Drummond AJ, Rambaut A (2007) BEAST: Bayesian evolutionary analysis by sampling trees. BMC Evol Biol 7:214

Drummond AJ, Ho SYW, Phillips MJ, Rambaut A (2006) Relaxed phylogenetics and dating with confidence. PLoS Biol 4:699-710

Emerson BC, Gillespie RG (2008) Phylogenetic analysis of community assembly and structure over space and time. Trends Ecol Evol 23:619-630

Ferreira MA, Suchard MA (2008). Bayesian analysis of elapsed times in continuous-time Markov chains. Can J Stat 36:355-368

Gudkov PK, Polyakova NE, Semina AV, Nazarkin MV (2010) Comparative morphological 
analysis of big scaled redfin Tribolodon hakonensis Günther, 1877 (Cyprinidae, Cypriniformes) from Sakhalin and Southern Primorye. J Ichthyol 50:740-744

Higuchi M, Goto A (1996) Genetic evidence supporting the existence of two distinct species in the genus Gasterosteus around Japan. Environ Biol Fishes 47:1-16

Iijima A, Tada R (1990) Evolution of Tertiary sedimentary basins of Japan in reference to opening of the Japan Sea. J Fac Sci, Univ Tokyo Sec 2: Geol Mineral Geogr Geophys $22: 121-171$

Imai C, Sakai H, Arai T (2008) Otolith Sr:Ca of an endangered cyprinid Tribolodon nakamurai indicating absence of sea-migrating traits. J Nat Fish Univ 57:137-141

Imoto JM, Saitoh K, Sasaki T, Yonezawa T, Adachi J, Kartavtsev YP, Miya M, Nishida M, Hanzawa N (2013) Phylogeny and biogeography of highly diverged freshwater fish species (Leuciscinae, Cyprinidae, Teleostei) inferred from mitochondrial genome analysis. Gene 514:112-124

Jolivet L, Tamaki K, Fournier M (1994) Japan Sea, opening history and mechanism: a synthesis. J Geophys Res 99:22237-22259

Kaneko T, Hasegawa S, Uchida K, Ogasawara T, Oyagi A, Hirano T (1999) Acid tolerance of Japanese dace (a cyprinid teleost) in Lake Osorezan, a remarkable acid lake. Zool Sci $16: 871-877$

Kartavtsev YF, Sviridov VV, Hanzawa N, Sasaki T (2002) Genetic divergence of Far-Eastern dace species belonging to the genus Tribolodon (Pisces, Cyprinidae) and closely related taxa. Russ J Genet 38:1285-1297

Kawabe T (1994) Biwako no oitachi (Formation of Lake Biwa). In: Research Group for Natural History of Lake Biwa (ed) Biwako no shizenshi (The natural history of Lake Biwa). Yasaka Shobo, Tokyo, pp 24-72

Kitagawa T, Yoshioka M, Kashiwagi M, Okazaki T (2001) Population structure and local differentiation in the delicate loach, Niwaella delicata, as revealed by mitochondrial DNA and morphological analyses. Ichthyol Res 48:127-135 
Kitamura A (2010) Formation and paleoenvironment of the Japanese Archipelago. In:

Watanabe K, Takahashi H (eds) Tansuigyorui chiri no shizenshi (Natural history of freshwater fish geography). Hokkaido University Press, Sapporo, pp 13-28

Kitamura A, Kimoto K (2006) History of the inflow of the warm Tsushima Current into the Sea of Japan between 3.5 and 0.8 Ma. Palaeogeogr Palaeoclimatol Palaeoecol $236: 355-366$

Kitano J, Mori S, Peichel CL (2007) Phenotypic divergence and reproductive isolation between sympatric forms of Japanese threespine sticklebacks. Biol J Linn Soc $91: 671-685$

Kitaura J, Wada K, Nishida M (1998) Molecular phylogeny and evolution of unique mud-using territorial behavior in ocypodid crabs (Crustacea: Brachyura: Ocypodidae). Mol Biol Evol 15:626-637

Kumar S, Stecher G, Tamura K (2016) MEGA7: molecular evolutionary genetics analysis version 7.0 for bigger datasets. Mol Biol Evol 33:1870-1874

Lindberg GU (1972) Large-scale fluctuations of sea level in the quaternary period: hypothesis based on biogeographic evidence. Nauka, Leningrad

MacDonald G (2003) Biogeography: introduction to space, time and life. Wiley

McDowall RM (2001) Diadromy, diversity and divergence: implications for speciation processes in fishes. Fish Fish 2:278-285

McDowall RM (2008) Diadromy, history and ecology: a question of scale. Hydrobiologia $602: 5-14$

Mizuno N (1987) Formation of freshwater fish fauna in Japan. In: Mizuno N, Goto A (eds) Freshwater fishes of Japan: their distribution, variation and speciation. Tokai University Press, Tokyo

Myers GS (1949) Salt tolerance of fresh-water fish groups in relation to zoogeographical problems. Bijdr Dierkd 28:315-322

Nakagawa H (2014) Contribution of environmental and spatial factors to the structure of 
stream fish assemblages at different spatial scales. Ecol Freshw Fish 23:208-223

Nakamura M (1969) Cyprinid fishes of Japan: studies on the life history of cyprinid fishes of Japan. Research Institute for Natural Resources, Tokyo

Nishimura S (1974) Nihon-kai no seiritsu (Formation of the Sea of Japan). Tsukiji-Shokan, Tokyo

Palumbi S, Martin A, Romano S, McMillian WO, Stice L, Grabowski G (1991) The simple fool's guide to PCR. Univ Hawaii, Honolulu

Polyakova NE, Semina AV, Brykov VA (2015) Analysis of mtDNA and nuclear markers points to homoploid hybrid origin of the new species of Far Eastern redfins of the genus Tribolodon (Pisces, Cyprinidae). Russ J Genet 51:1075-1087

Rambaut A (2016) FigTree Version 1.4.3. http://tree.bio.ed.ac.uk/ software/figtree/. Accessed 23 March 2017

Rambaut A, Drummond AJ, Suchard M (2013) Tracer version 1.6. http:// tree.bio. ed.ac.uk/software/tracer/. Accessed 23 March 2017

Ryazanova IN, Polyakova NE (2012) Differentiation of large scaled redfin Tribolodon hakonensis (Pisces, Cyprinidae) in the Russian part of the range as inferred from the data of karyological analysis and PCR RFLP analysis of mitochondrial DNA. Russ J Genet 48:199-207

Saitoh K, Sado T, Mayden RL, Hanzawa N, Nakamura K, Nishida M, Miya M (2006) Mitogenomic evolution and interrelationships of the Cypriniformes (Actinopterygii: Ostariophysi): the first evidence toward resolution of higher-level relationships of the World's largest freshwater fish clade based on 59 whole mitogenome sequences. J Mol Evol 63:826-841

Sakai H (1995) Life-history and genetic divergence in three species of Tribolodon (Cyprinidae). Mem Fac Fish Hokkaido Univ 42:1-98

Sakai H, Amano S (2014) A new subspecies of anadromous Far Eastern dace, Tribolodon brandtii maruta subsp. nov. (Teleostei, Cyprinidae) from Japan. Bull Natl Mus Nat Sci 
Ser A 40:219-229

Sakai H, Hamada K (1985) Electrophoretic discrimination of Tribolodon species (Cyprinidae) and the occurrence of their hybrids. Jpn J Ichthyol 32:216-224

Sakai H, Imai C (2002) Otolith Sr:Ca ratios of the freshwater and anadromous cyprinid genus Tribolodon. Ichthyol Res 52:182-184

Sakai H, Goto A, Jeon SR (2002) Speciation and dispersal of Tribolodon species (Pisces, Cyprinidae) around the Sea of Japan. Zool Sci 19:1291-1303

Sakai H, Ito Y, Shedko SV, Safronov SN, Frolov SV, Chereshnev IA, Jeon SR, Goto A (2006) Phylogenetic and taxonomic relationships of Northern Far Eastern phoxinin minnows, Phoxinus and Rhynchocypris (Pisces, Cyprinidae), as inferred from allozyme and mitochondrial 16S rRNA sequence analyses. Zool Sci 23:323-331

Sasaki T, Kartavtsev YP, Chiba SN, Uematsu T, Sviridov VV, Hanzawa N (2007) Genetic divergence and phylogenetic independence of Far Eastern species in subfamily Leuciscinae (Pisces: Cyprinidae) inferred from mitochondrial DNA analyses. Genes Genet Syst 82:329-340

Semina AV, Polyakova NE, Brykov VA (2006) Genetic analysis identifies a cryptic species of Far Eastern daces of the genus Tribolodon. Doklady Biol Sci 407:173-175

Stamatakis A (2014) RAxML version 8: a tool for phylogenetic analysis and post-analysis of large phylogenies. Bioinformatics 30:1312-1313

Tabata R, Kakioka R, Tominaga K, Komiya T, Watanabe K (2016) Phylogeny and historical demography of endemic fishes in Lake Biwa: the ancient lake as a promoter of evolution and diversification of freshwater fishes in western Japan. Ecol Evol 6:2601-2623

Tada R (1994) Paleoceanographic evolution of the Japan Sea. Palaeogeogr Palaeoclimatol Palaeoecol 108: 487-508

Takahashi H, Møller PR, Shedko SV, Ramatulla T, Joen SR, Zhang CG, Sideleva VG, Takata K, Sakai H, Goto A, Nishida M (2016) Species phylogeny and diversification process of Northeast Asian Pungitius revealed by AFLP and mtDNA markers. Mol Phylogenet Evol 


\section{9:44-52}

Templeton AR (2006) Population genetics and microevolutionary theory. Wiley

Templeton AR, Sing CF (1993) A cladistic analysis of phenotypic associations with

haplotypes inferred from restriction endonuclease mapping. IV. Nested analyses with cladogram uncertainty and recombination. Genetics 134:659-669

Ward RD, Zemlak TS, Innes BH, Last PR, Hebert PDN (2005) Barcoding Australia's fish species. Philos Trans R Soc Lond B Biol Sci. 360:1847-1857

Watanabe K (2012) Faunal structure of Japanese freshwater fishes and its artificial disturbance. Environ Biol Fishes 94:533-547

Watanabe K, Takahashi H (2010) Tansuigyorui chiri no shizenshi (Natural history of freshwater fish geography). Hokkaido University Press, Sapporo

Watanabe K, Iguchi K, Hosoya K, Nishida M (2000) Phylogenetic relationships of the Japanese minnows, Pseudorasbora (Cyprinidae), as inferred from mitochondrial 16S rRNA gene sequences. Ichthyol Res 47:43-50

Watanabe K, Kano Y, Takahashi H, Mukai T, Kakioka R, Tominaga K (2010) GEDIMAP: a database of genetic diversity for Japanese freshwater fishes. Ichthyol Res 57:107-109

Watanabe K, Tominaga K, Nakajima J, Kakioka R, Tabata R (2016) Japanese freshwater fishes: biogeography and cryptic diversity. In: M. Motokawa and H. Kajihara (eds) Species diversity of animals in Japan, diversity and commonality in animals. Springer, Tokyo, pp 183-227

Yamamoto S, Morita K, Kitano S, Watanabe K, Koizumi I, Maekawa K, Takamura K (2004) Phylogeography of white-spotted charr (Salvelinus leucomaenis) inferred from mitochondrial DNA sequences. Zool Sci 21:229-240

Yokoyama T (1988) Seinan Nihon no Shizenshi (Natural history of southwestern Japan). Sanwashobo, Tokyo

Yokoyama R, Goto A (2005) Evolutionary history of freshwater sculpins, genus Cottus (Teleostei; Cottidae) and related taxa, as inferred from mitochondrial DNA phylogeny. 
Mol Phylogenet Evol 36:654-668

Yonekura N, Kaizuka S, Nogami M, Chinzai K (2001) Regional geomorphology of the Japanese Islands, vol 1. Introduction to Japanese geomorphology. University of Tokyo Press, Tokyo

Zardoya R, Doadrio I (1999) Molecular evidence on the evolutionary and biogeographical patterns of European cyprinids. J Mol Evol 49:227-237 


\section{Figure legends}

Fig. 1 Distribution ranges of four Tribolodon species with two sub- species (shaded area). "?" denotes area lacking information. Drawn after Sakai (1995) and Brykov et al. (2013)

Fig. 2 Sampling localities of four Tribolodon species. Closed squares, T. brandtii; open circles, T. sachalinensis; triangles, T. nakamurai; closed circles, T. hakonensis

Fig. 3 ML tree of Tribolodon and closely related species based on partial cyt $b$ sequences (758 bp; "short sequences"). Intraspecific haplotype groups are labeled, e.g., TBB1. Numbers at internodes represent bootstrap probability values $(\geq 70 \%)$ for 1,000 replicates

Fig. 4 Bayesian time-calibrated tree of Tribolodon and closely related species based on partial mtDNA sequences (2,941 bp from cytb, COI, and 16S; "long sequences"). Intraspecific haplotype groups are labeled, e.g., TBB1. Numbers at internodes represent Bayesian posterior probability $(\geq 0.9) / \mathrm{ML}$ bootstrap probability ( $\geq 70 \%)$. Nodes with circled numbers are those referred to in the text. Node $8(*)$ is the node at which the geographic calibration was applied (see "Materials and methods")

Fig. 5 Haplotype network of Tribolodon brandtii with a distribution map of haplotype groups. Abbreviations of haplotype groups correspond to those of Figs. 3 and 4. Haplotype groups are represented by different symbols on the map. Broken lines indicate the boundaries of distribution of haplotype groups. Shaded areas represent the distribution of the species. The sizes of circles in networks reflect the relative frequency of haplotypes. Only major haplotypes are labeled in the network. Black dots represent missing haplotypes not detected among our samples

Fig. 6 Haplotype network of Tribolodon nakamurai with distribution map. Shaded areas represent the distribution of the species. The sizes of circles in networks reflect the relative 
frequency of haplotypes. Black dots represent missing haplotypes not detected among our samples

Fig. 7 Haplotype network of Tribolodon sachalinensis with distribution map. Shaded areas represent the distribution of the species. The sizes of circles in networks reflect the relative frequency of haplotypes. Only major haplotypes are labeled in the network. Black dots represent missing haplotypes not detected among our samples. The localities of haplotypes showing differentiation from major haplotypes with several missing haplotypes $(\mathrm{sa10}, 17)$ are indicated by symbols on the map

Fig. 8 Haplotype network of Tribolodon hakonensis with distribution map. Abbreviations of haplotype groups correspond to those of Figs. 3 and 4. Networks and distribution maps represent one or two haplotype groups $(\mathbf{a}-\mathbf{d})$. Broken lines indicate the distribution boundaries of the haplotype groups. Shaded areas represent the distribution of the species. The sizes of circles in networks reflect the relative frequency of different haplotypes. Only major haplotypes are labeled in the network. Black dots represent missing haplotypes not detected among our samples. Arrowhead in the network of each group indicates the root position in the overall network (e). Arrows in maps indicate the direction of range expansion that was inferred from the tip and interior relationship of haplotypes in the network 
Table 1 Localities, sample size $(n)$, and haplotype frequencies of four species of Tribolodon and comparative species

\begin{tabular}{|c|c|c|c|c|c|c|}
\hline Code & River system & Locality & $n$ & Group $\left(n^{l}\right)$ & Haplotype $\left(n^{2}\right)$ & GEDIMAP ID \\
\hline \multicolumn{7}{|c|}{ Tribolodon brandtii brandtii } \\
\hline 4 & Mukawa River & Hokkaido & 2 & TBB1 & bb07, bb09 & P2201 \\
\hline 9 & Omono R. & Akita & 2 & TBB1 & $\mathrm{bb} 02(2)$ & $\mathrm{P} 2202$ \\
\hline 14 & Shinano R. & Niigata & 5 & TBB1 & $\begin{array}{l}\text { bb01, bb02, bb06(2), } \\
\text { bb08* }\end{array}$ & P2203 \\
\hline 16 & Oyabe R. & Toyama & 9 & TBB1 & $\begin{array}{l}\text { bb01*, bb03*(6), bb04, } \\
\text { bb05 }\end{array}$ & P2204 \\
\hline 44 & Busse Lagoon & Sakhalin, Russia & 4 & TBB1 & bb06*, bb08(3) & $\mathrm{P} 2205$ \\
\hline 47 & Peter the Great Bay & Primorsky, Russia & 2 & TBB2 & bb10, bb11* & P2206 \\
\hline 49 & Songchon R. & Korea & 5 & TBB2 & bb10, bb11(4) & P2207 \\
\hline \multicolumn{7}{|c|}{ T. brandtii maruta } \\
\hline 18 & Ofunato Bay & Iwate & 5 & TBM & bm01, bm02(4)* & P2208 \\
\hline 20 & Kasumigaura Lake & Ibaraki & 4 & TBM & bm01(3), bm03* & P2209 \\
\hline 21 & Tama R. & Tokyo & 1 & TBM & bm01 & P2210 \\
\hline 22 & Tokyo Bay & Tokyo & 5 & TBM & bm01(5) & P2211 \\
\hline \multicolumn{7}{|c|}{ T. sachalinensis } \\
\hline 1 & Teshio R. & Hokkaido & 8 & $\mathrm{TS}$ & $\begin{array}{l}\mathrm{sa} 01^{*}, \mathrm{sa} 03, \mathrm{sa} 04, \mathrm{sa} 07, \\
\mathrm{sa} 08, \mathrm{sa} 12^{*}, \mathrm{sa} 15^{*}(2)\end{array}$ & $\mathrm{P} 2212$ \\
\hline 2 & Tokoro R. & Hokkado & 5 & TS & $\operatorname{sa} 17^{*}(5)$ & P2213 \\
\hline 3 & Ishikari R. & Hokkaido & 9 & TS & $\begin{array}{l}\text { sa02, sa06*, sa10, sa } 11, \\
\text { sa13*(3), sa14, sa16 }\end{array}$ & $\mathrm{P} 2214$ \\
\hline 4 & Mukawa River & Hokkaido & 3 & TS & $\mathrm{sa01(3)}$ & P2215 \\
\hline 6 & Tanabu River & Aomori & 18 & TS & $\mathrm{sa01(18)}$ & $\mathrm{P} 2216$ \\
\hline 12 & Mogami River & Yamagata & 3 & TS & $\mathrm{sa} 05(3)$ & P2217 \\
\hline 45 & Lyutoga R. & Sakhalin, Russia & 3 & TS & sa04, sa9*, sa17 & $\mathrm{P} 2218$ \\
\hline 46 & Tumnin R. & Primorsky, Russia & 8 & TS & $\mathrm{sa06}(8)$ & P2219 \\
\hline \multicolumn{7}{|c|}{ T. nakamurai } \\
\hline 10 & Koyoshi R. & Akita & 1 & $\mathrm{TN}$ & n01 & P2220 \\
\hline 12 & Mogami R. & Yamagata & $4^{3}$ & $\mathrm{TN}$ & $\mathrm{n} 02 *(3), \mathrm{n} 03$ & P2221 \\
\hline 13 & Agano R. & Niigata & $2^{3}$ & $\mathrm{TN}$ & $\mathrm{n} 01, \mathrm{n} 02$ & P2222 \\
\hline \multicolumn{7}{|c|}{ T. hakonensis } \\
\hline 1 & Teshio R. & Hokkaido & 2 & TH1(1), TH3(1) & h04*, h37 & P2223 \\
\hline 2 & Tokoro R. & Hokkado & 2 & TH1 & $\mathrm{h} 01 *(2)$ & P2224 \\
\hline 3 & Ishikari R. & Hokkaido & 1 & TH3 & h51 & P2225 \\
\hline 5 & Ohno R. & Hokkaido & 2 & TH1(1), TH3(1) & h03, h42* & P2226 \\
\hline 7 & Ohata R. & Aomori & 10 & TH3 & h37, h42, h46, h52(7) & P2227 \\
\hline 8 & Osorezan L. & Aomori & 11 & TH3 & h47(8), h49, h50(2) & $\mathrm{P} 2228$ \\
\hline 11 & Nikko R. & Yamagata & 9 & TH3(7), TH4(2) & $\begin{array}{l}\text { h37(2), h39*, h42(3), } \\
\text { h43, h60*, h61 }\end{array}$ & P2229 \\
\hline 15 & Chikuma R. & Nagano & 12 & TH3(9), TH4(3) & $\begin{array}{l}\text { h37(2), h39, h42(4), } \\
\text { h44, h45, h60(2), h62 }\end{array}$ & $\mathrm{P} 2230$ \\
\hline 17 & Kozuchi R. & Iwate & 7 & TH2(3), TH3(4) & h06*(2), h08*, h37*(4) & $\mathrm{P} 2231$ \\
\hline 18 & Ofunato Bay & Iwate & 10 & TH3 & h37(7), h38(2), h52 & P2232 \\
\hline 19 & Kinu R. & Tochigi & 6 & TH2 & h06(4), h07, h08 & P2233 \\
\hline 21 & Tama R. & Tokyo & 1 & TH4 & h54 & P2234 \\
\hline 23 & Kaname R. & Kanagawa & 9 & TH2 & h06(8), h09 & $\mathrm{P} 2235$ \\
\hline 24 & Tenryu R. & Shizuoka & 3 & TH4 & h54(2), h62* & $\mathrm{P} 2236$ \\
\hline 25 & Toyo R. & Aichi & 9 & TH4 & h58(9) & $\mathrm{P} 2237$ \\
\hline 26 & Kiso R. & Gifu & 10 & TH4 & $\begin{array}{l}\text { h53*, h54(6), h58(2), } \\
\text { h59* }\end{array}$ & P2238 \\
\hline 27 & Miya R. & Mie & 4 & TH4 & h54(3), h55 & P2239 \\
\hline 28 & Koza R. & Wakayama & 4 & TH4 & h54, h56*(2), h57 & P2240 \\
\hline 29 & Ado R. & Shiga & 20 & TH5 & $\begin{array}{l}\text { h10(2), h11, H12(7), } \\
\text { h33(4), h34(4), h35(2) }\end{array}$ & P2241 \\
\hline 30 & Lake Biwa & Shiga & 16 & TH5 & $\begin{array}{l}\text { h10*(7), h12(4), } \\
\text { h33*(4), h34 }\end{array}$ & P2242 \\
\hline 31 & Kita R. & Fukui & 20 & TH5 & $\begin{array}{l}\text { h27*, h28(11), h29(6), } \\
\text { h30(2) }\end{array}$ & P2243 \\
\hline 32 & Minami R. & Fukui & 20 & TH5 & h28(17), h29(3) & P2244 \\
\hline 33 & Ibo R. & Hyogo & 10 & TH5 & h28(2), h32(4), h36(4) & $\mathrm{P} 2245$ \\
\hline 34 & Takahashi R. & Okayama & 8 & TH5 & h19(4), h24(4) & P2246 \\
\hline 35 & Kando R. & Shimane & 7 & TH5 & h24(6), h31 & P2247 \\
\hline 36 & Kotou R. & Yamaguchi & 6 & TH5 & h19(4), h20(2) & $\mathrm{P} 2248$ \\
\hline 37 & Awano Harbor & Yamaguchi & 9 & TH5 & h19(6), h24(3) & P2249 \\
\hline
\end{tabular}




\begin{tabular}{|c|c|c|c|c|c|c|}
\hline 38 & Shimanto R. & Kochi & 10 & TH5 & $\begin{array}{l}\text { h13*(2), h14(2), h15, } \\
\text { h16, h17, h18*(3) }\end{array}$ & $\mathrm{P} 2250$ \\
\hline 39 & Oita R. & Oita & 5 & TH5 & h19(4), h21 & P2251 \\
\hline 40 & Matsuura R. & Saga & 11 & TH6 & h66*(10), h67 & $\mathrm{P} 2252$ \\
\hline 41 & Chikugo R. & Fukuoka & 1 & TH5 & $\mathrm{h} 23^{*}$ & P2253 \\
\hline 42 & Sendai R. & Kagoshima & 10 & TH5 & h22, h25, h26(8) & P2254 \\
\hline 43 & Sago R. & $\begin{array}{l}\text { Tsushima Island, } \\
\text { Nagasaki }\end{array}$ & 10 & TH6 & h68(10) & P2255 \\
\hline 44 & Busse Lagoon & Sakhalin, Russia & 3 & TH1(1), TH3(2) & h05, h40, h48 & P2256 \\
\hline 45 & Lyutoga R. & Sakhalin, Russia & 1 & TH3 & $\mathrm{h} 41^{*}$ & P2257 \\
\hline 46 & Tumnin R. & Primorsky, Russia & 8 & TH1(3), TH3(5) & $\begin{array}{l}\text { h01, h02(2), h37(2), } \\
\text { h47(3) }\end{array}$ & P2258 \\
\hline 47 & Peter the Great Bay & Primorsky, Russia & 2 & TH6 & h64(2) & P2259 \\
\hline 48 & Samchokoship & Korea & 3 & TH6 & h63*, h64, h65 & $\mathrm{P} 2260$ \\
\hline \multicolumn{7}{|c|}{ Pseudaspius leptocephalus } \\
\hline & $\begin{array}{l}\text { Chita R., Amur R. } \\
\text { basin }\end{array}$ & Chita, Russia & 1 & & & \\
\hline \multicolumn{7}{|c|}{ Rhynchocypris lagowskii steindachneri } \\
\hline \multirow{2}{*}{\multicolumn{7}{|c|}{ Rhynchocypris oxycephalus }} \\
\hline & & & & & & \\
\hline & Ishida R. & Shiga & 1 & & & \\
\hline
\end{tabular}

Locality codes correspond to those of Fig. 1

Group names correspond to those of Figs. 3, 4, 5, 6, 7, 8

${ }^{1}$ Number of specimens when two or more groups coexisted

${ }^{2}$ Number of specimens (only shown for haplotypes with $\geq 2$ )

${ }^{3}$ Including sequences from database

*Haplotypes for which longer sequences were obtained 

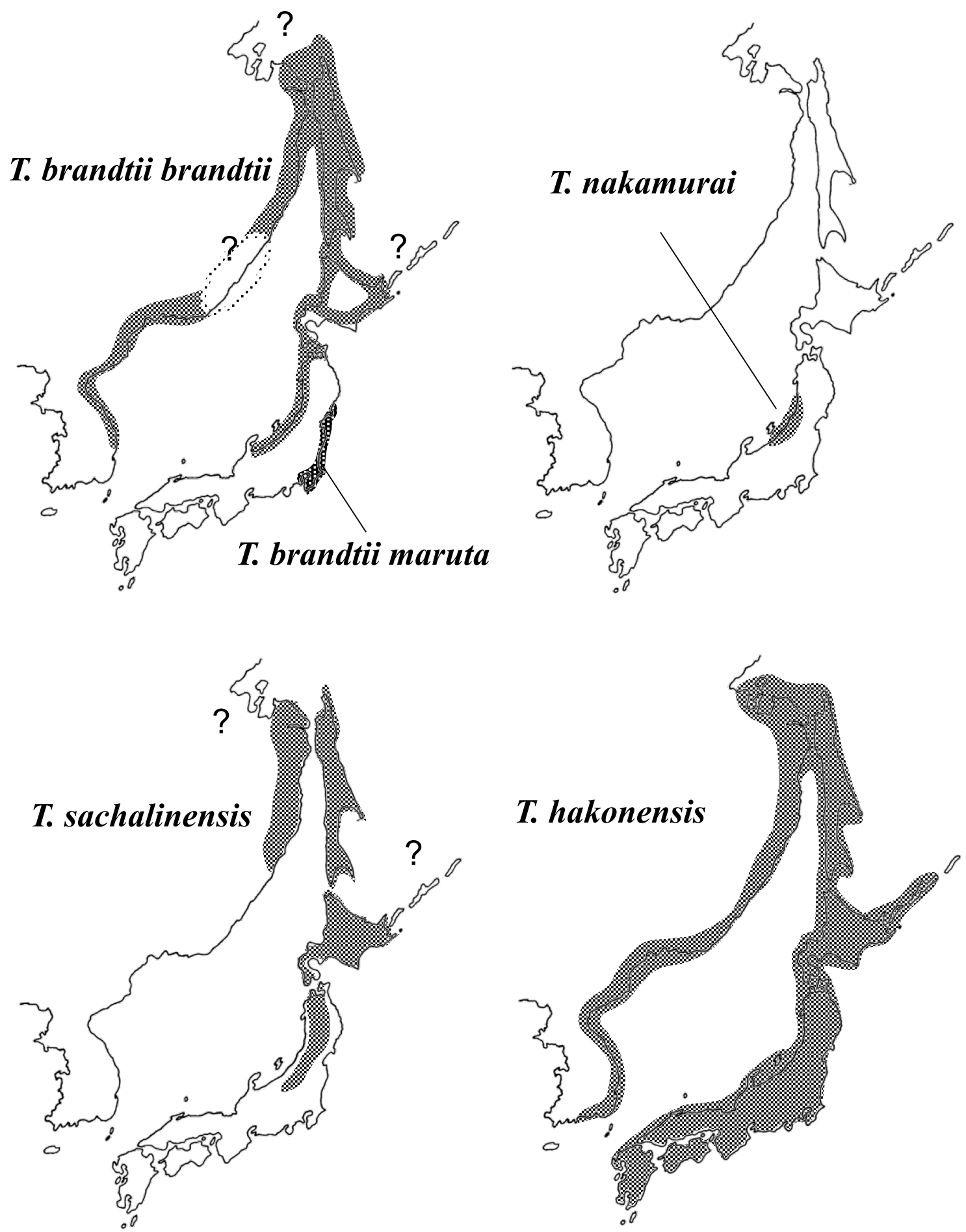

个Fig.1 


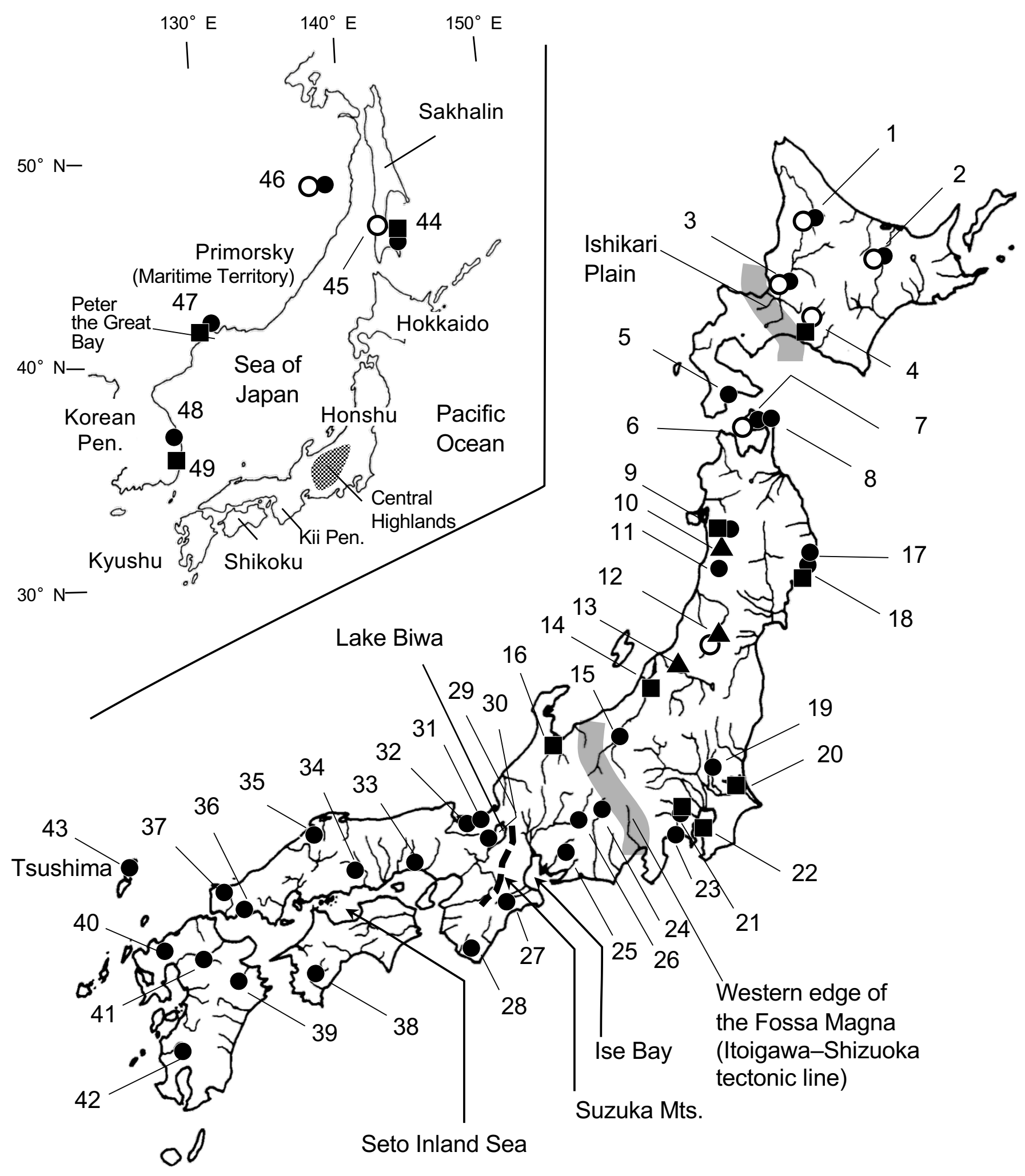




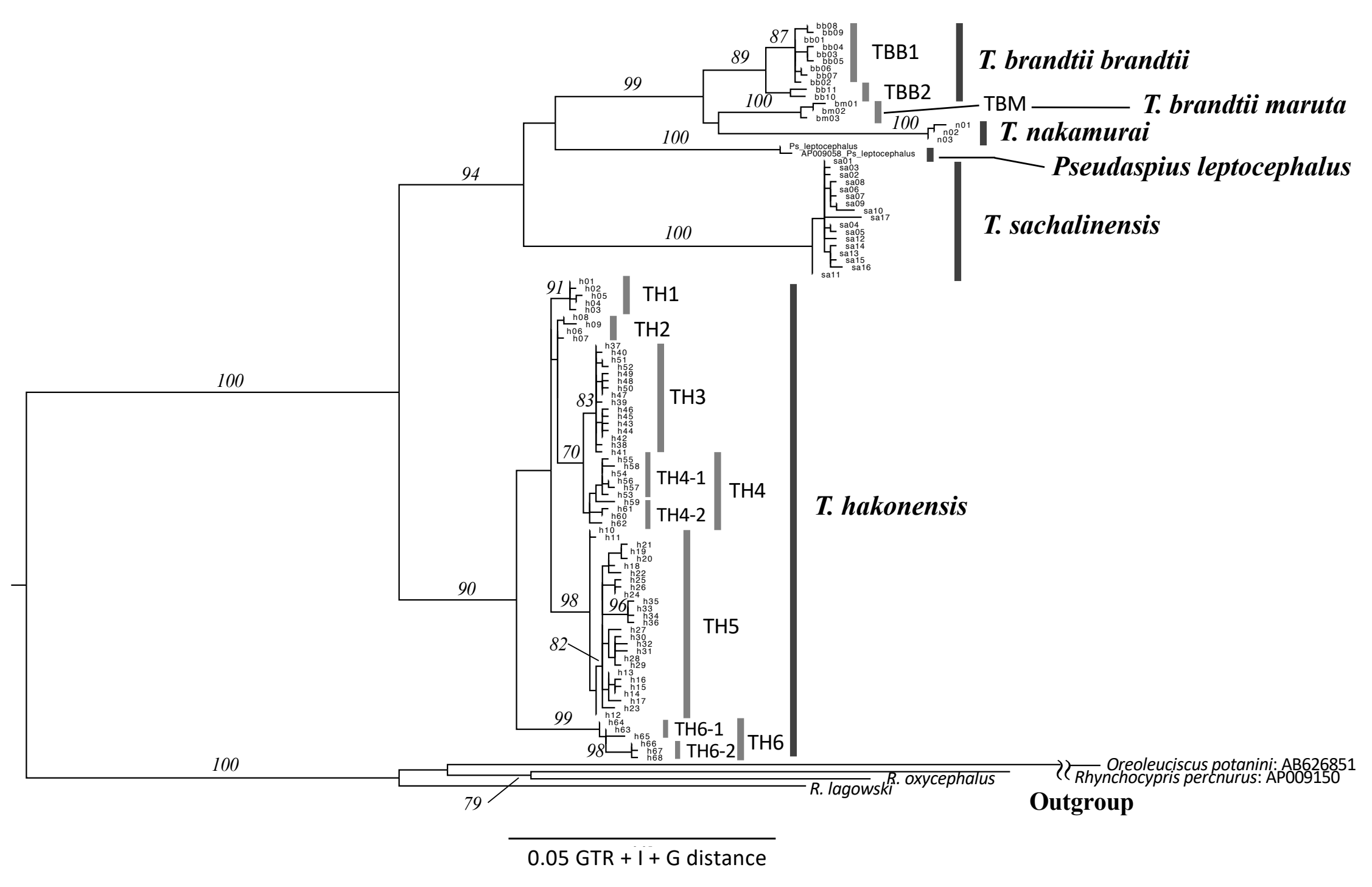




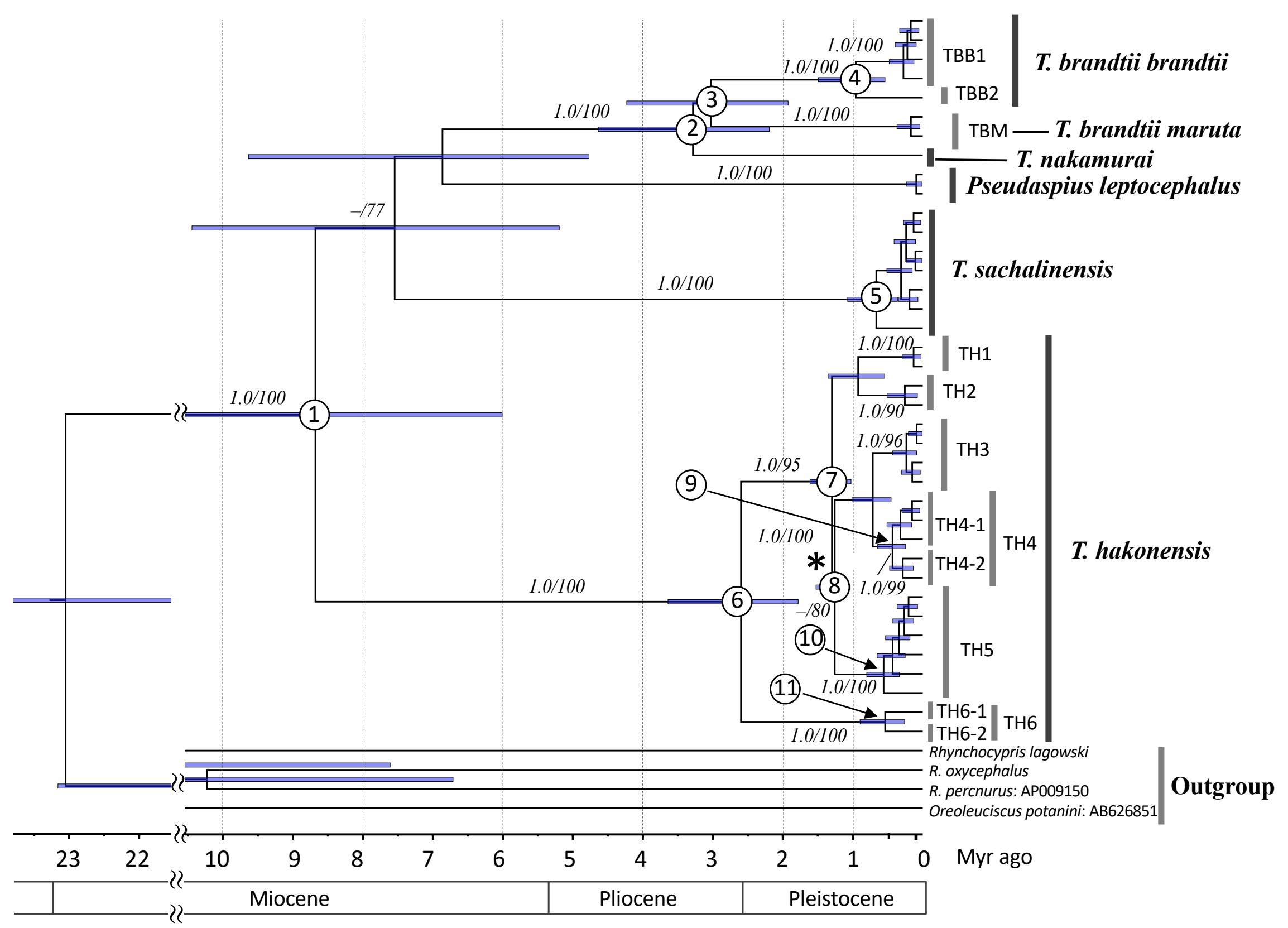




\section{Tribolodon brandtii}

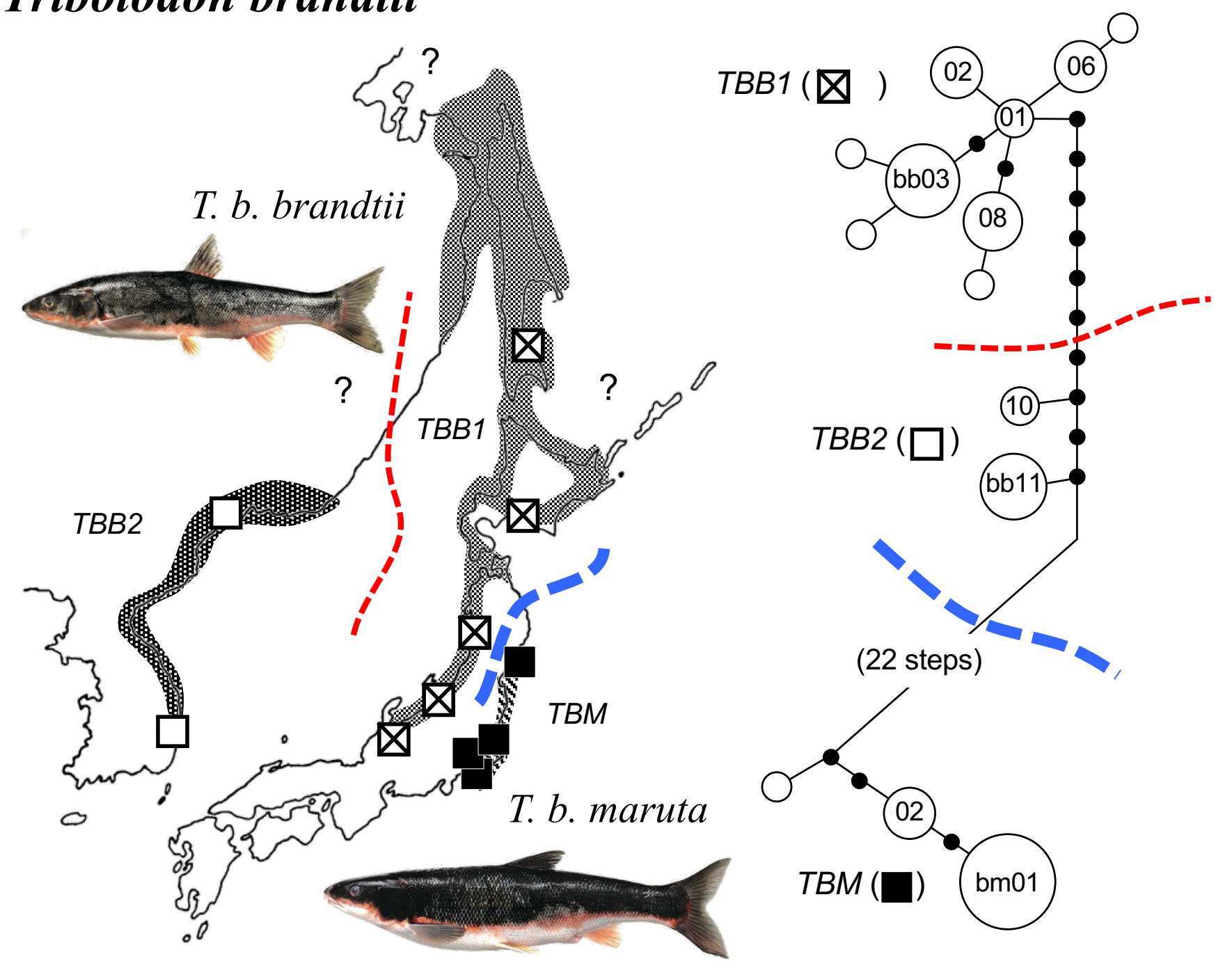




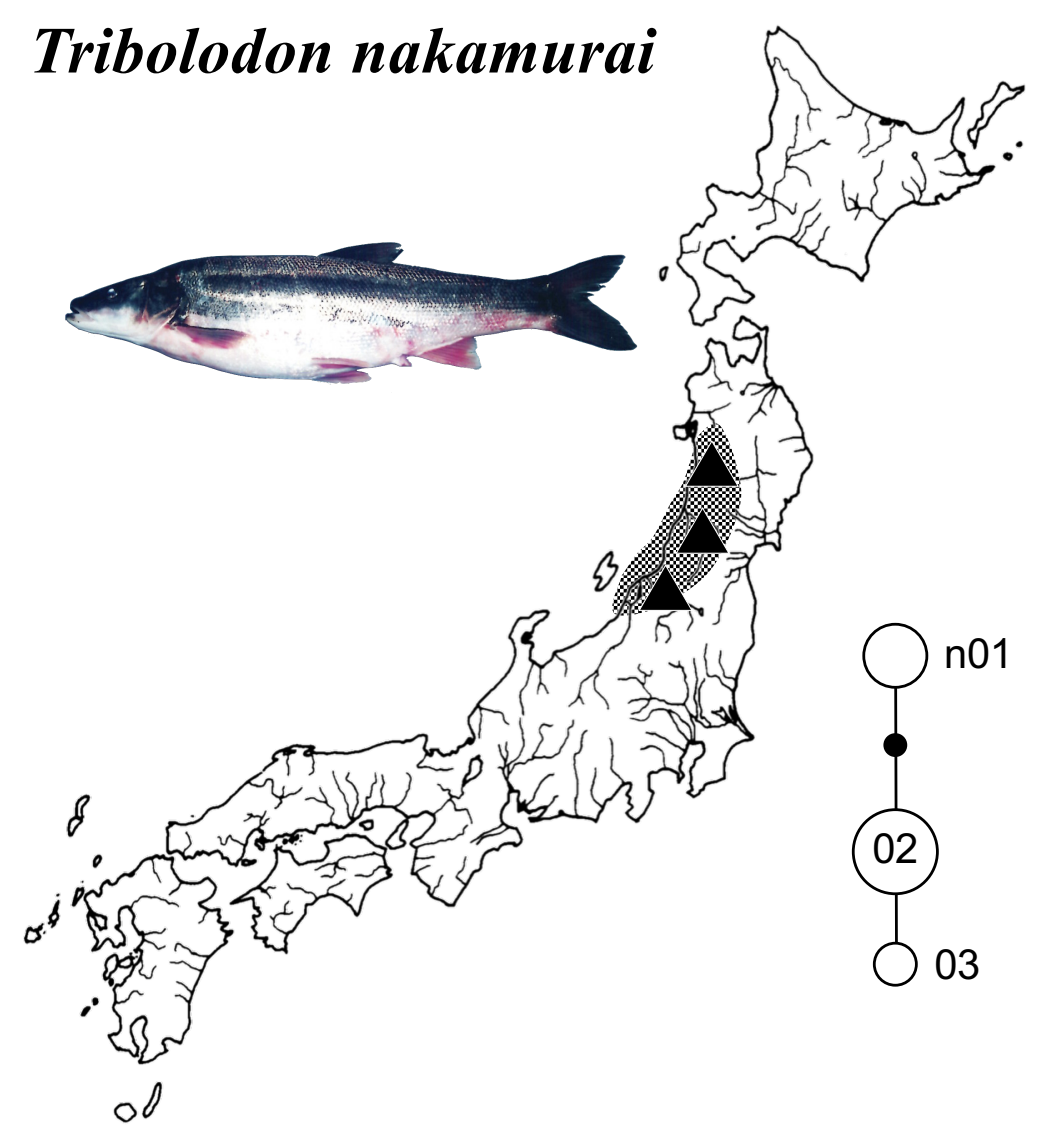

个Fig. 6 


\section{Tribolodon sachalinensis}

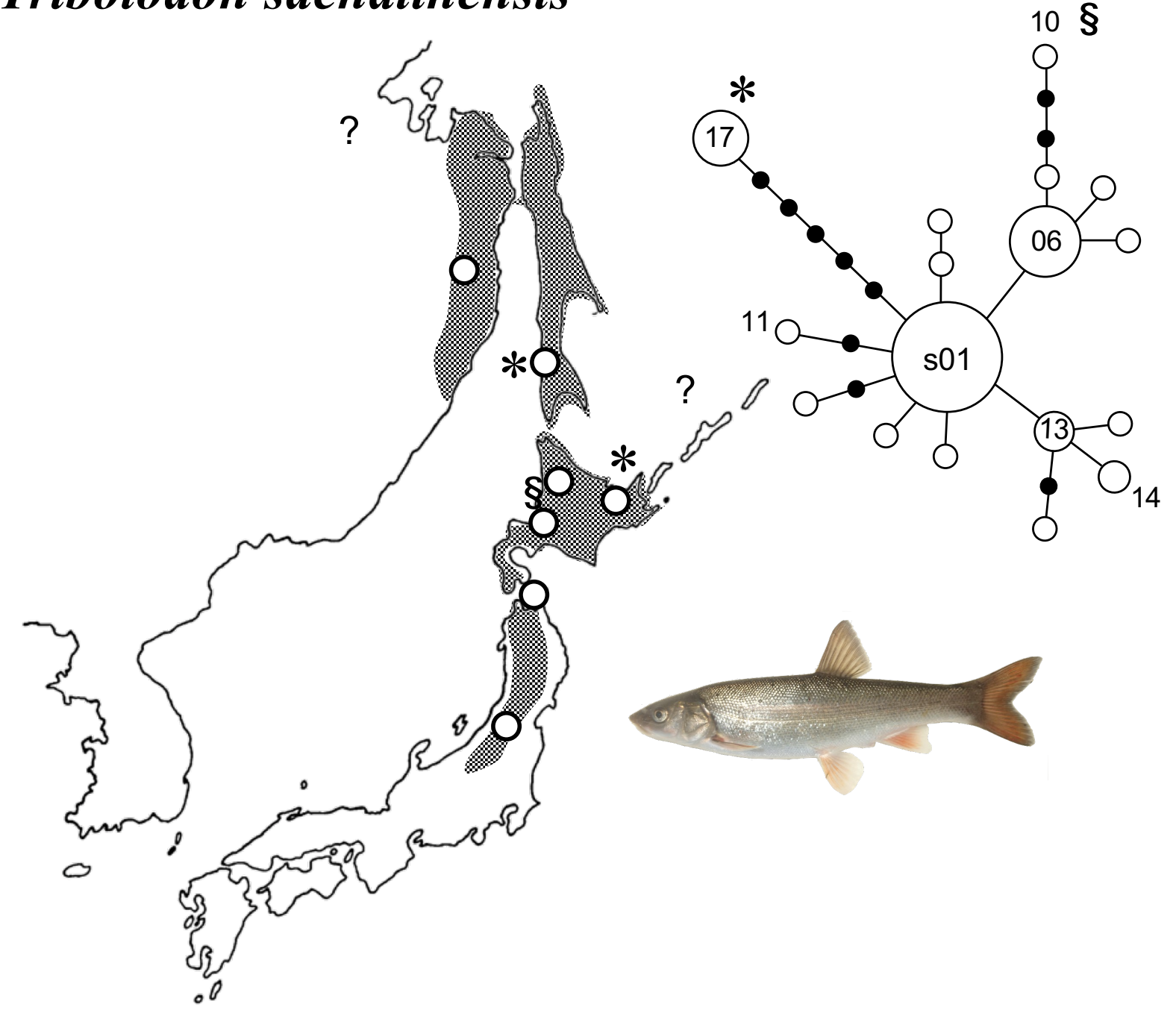

个Fig. 7 


\section{Tribolodon hakonensis}
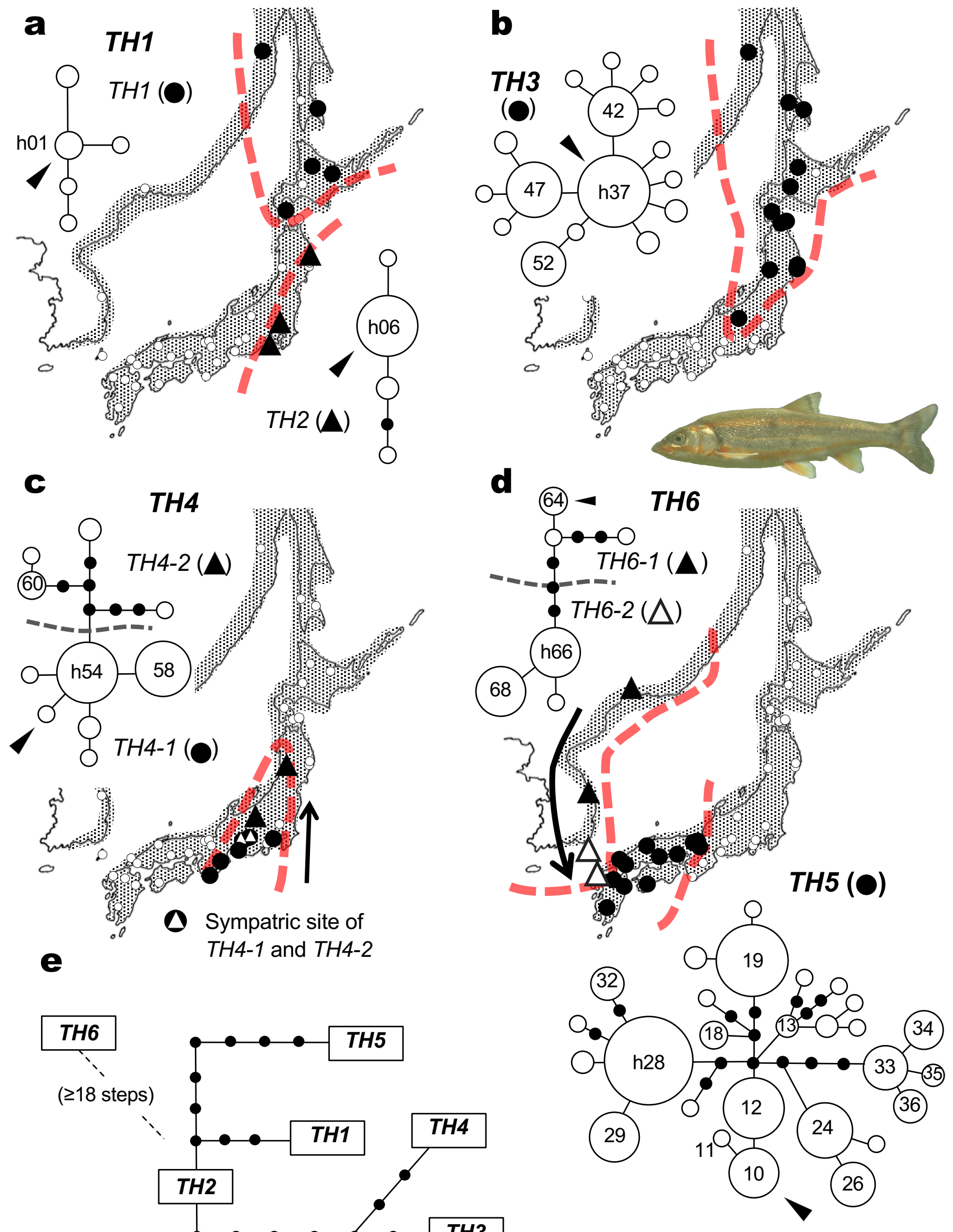

TH3

个Fig. 8 


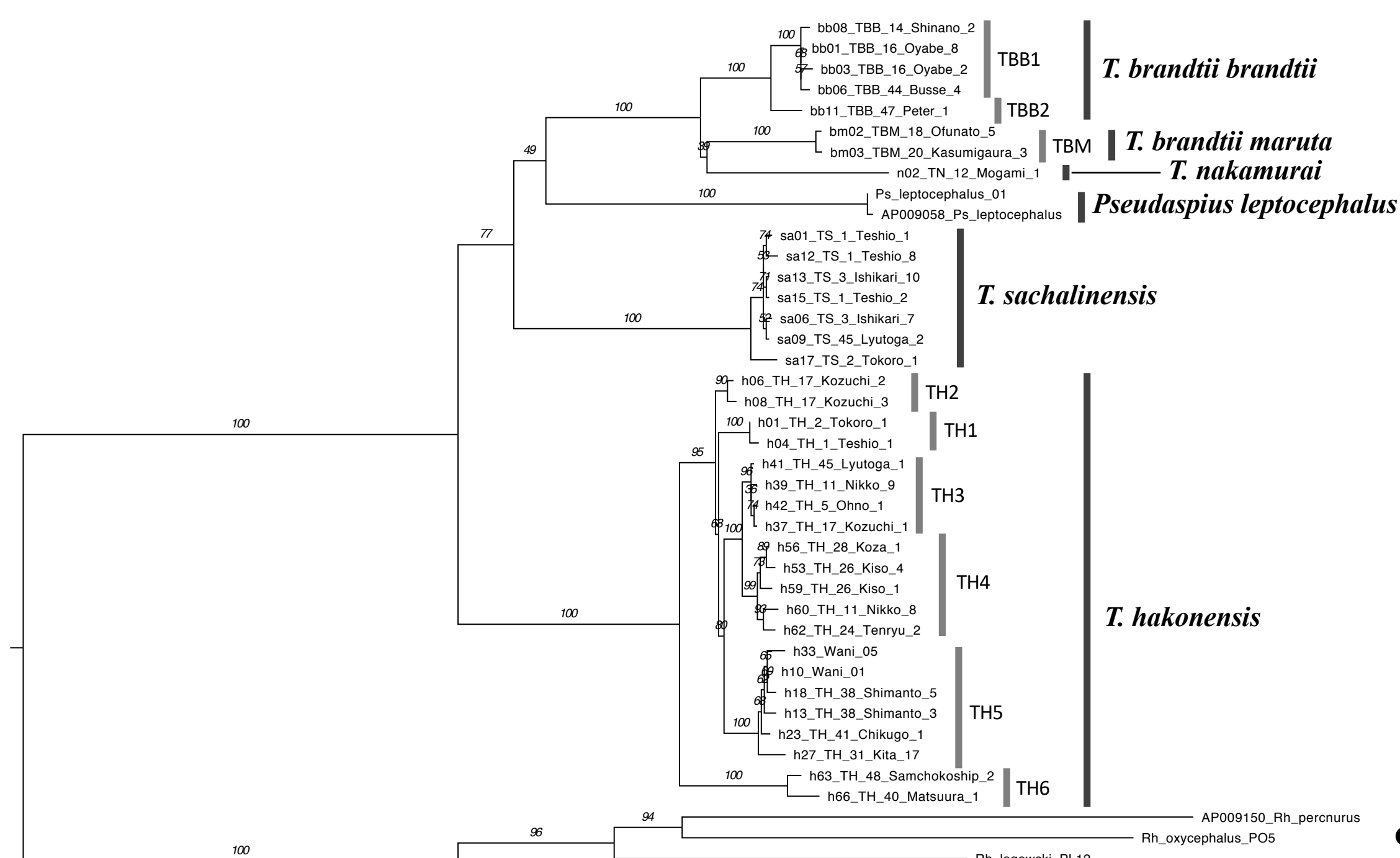

Outgroup

$\overline{0.02 \mathrm{GTR}+\mathrm{I}+\mathrm{G} \text { distance }}$

ESM Fig. S1 ML tree of Tribolodon and closely related species based on partial mtDNA sequences (2,941 bp from cytb, COI, and 16S; "long sequences"). OTU labels denote the haplotype name, species/subspecies code, locality code, and specimen ID. Numbers at internodes denote bootstrap probability values for 1,000 replicates 

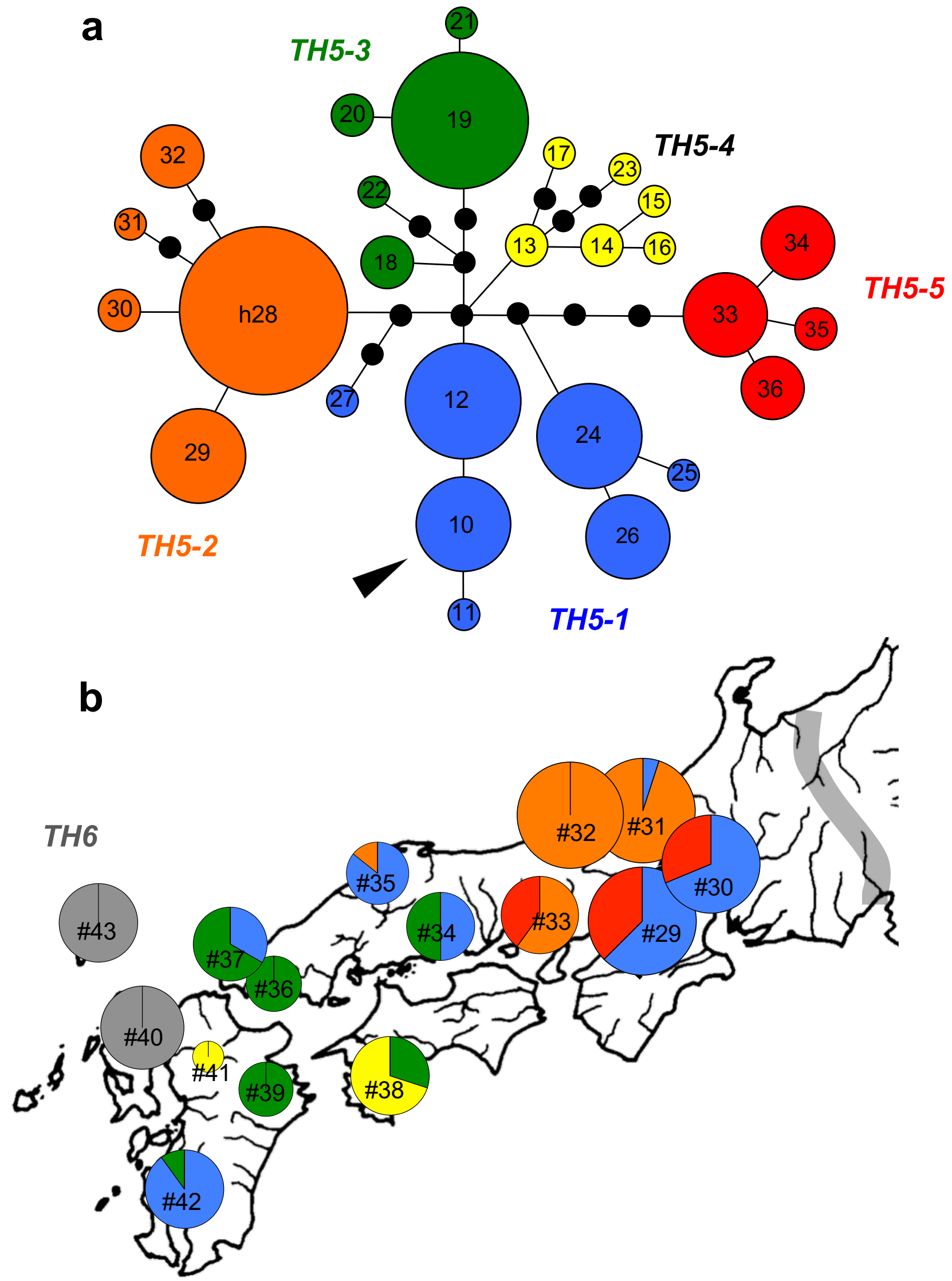

ESM Fig. S2 Subgroups of the haplotype group TH5 of Tribolodon hakonensis (a) and distribution map (b). Grouping was conducted by the nesting rule (Templeton and Sing 1993), and 2-step clades (TH5-1TH5-5) are indicated by different colors. Arrowhead in the network indicates the position of the root based on the overall network of $T$. hakonensis (see Fig. 8e). Haplotype frequencies in local samples (denoted with \#) are expressed by pie charts 


\section{a Tribolodon brandtii}

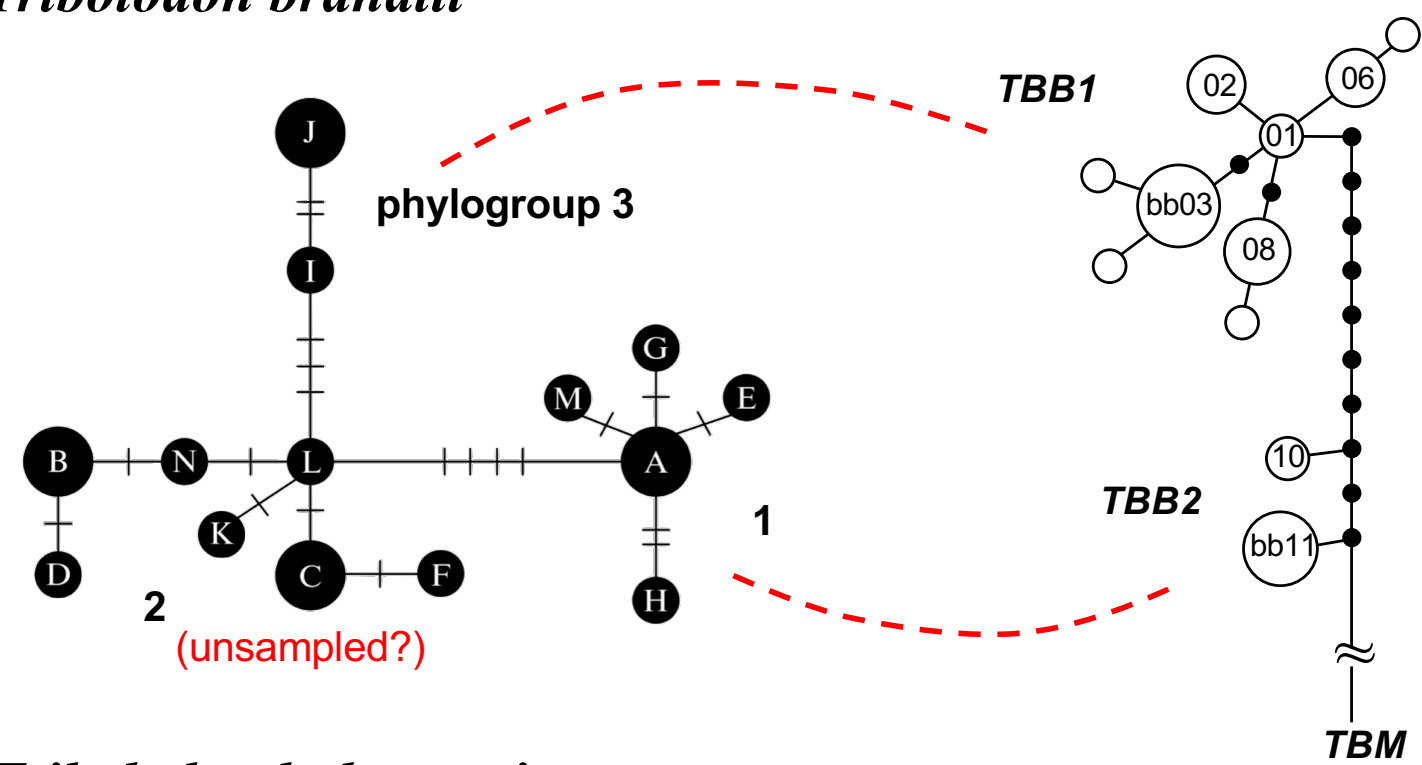

b Tribolodon hakonensis

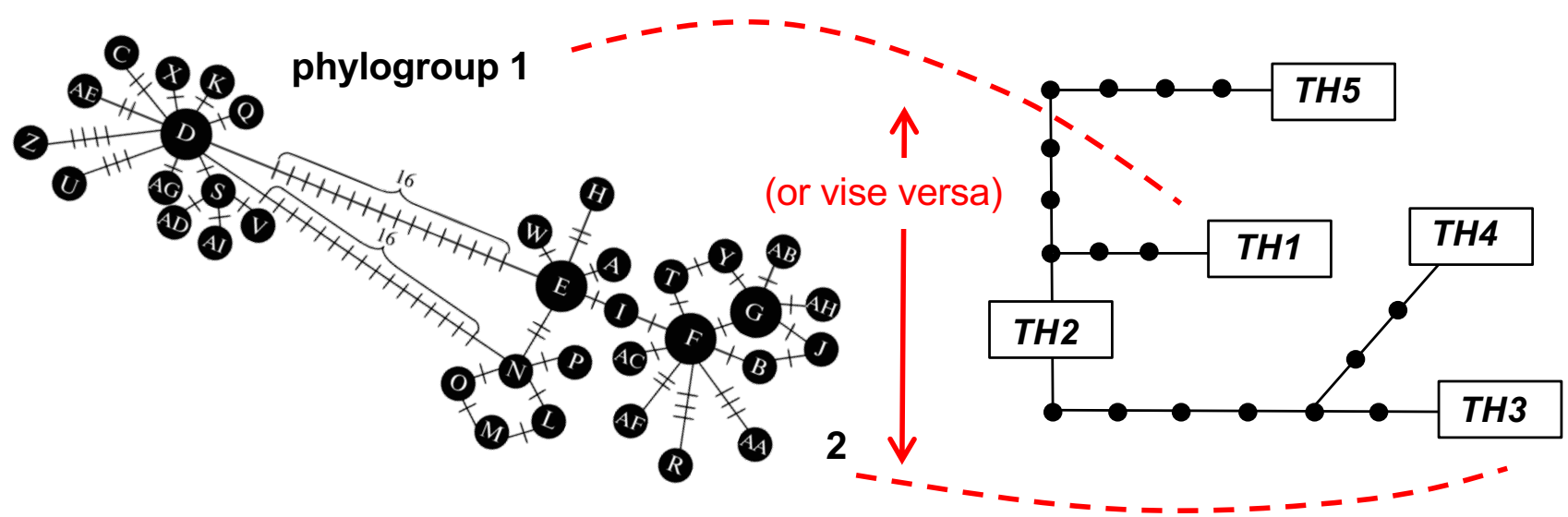

c Tribolodon sachalinensis

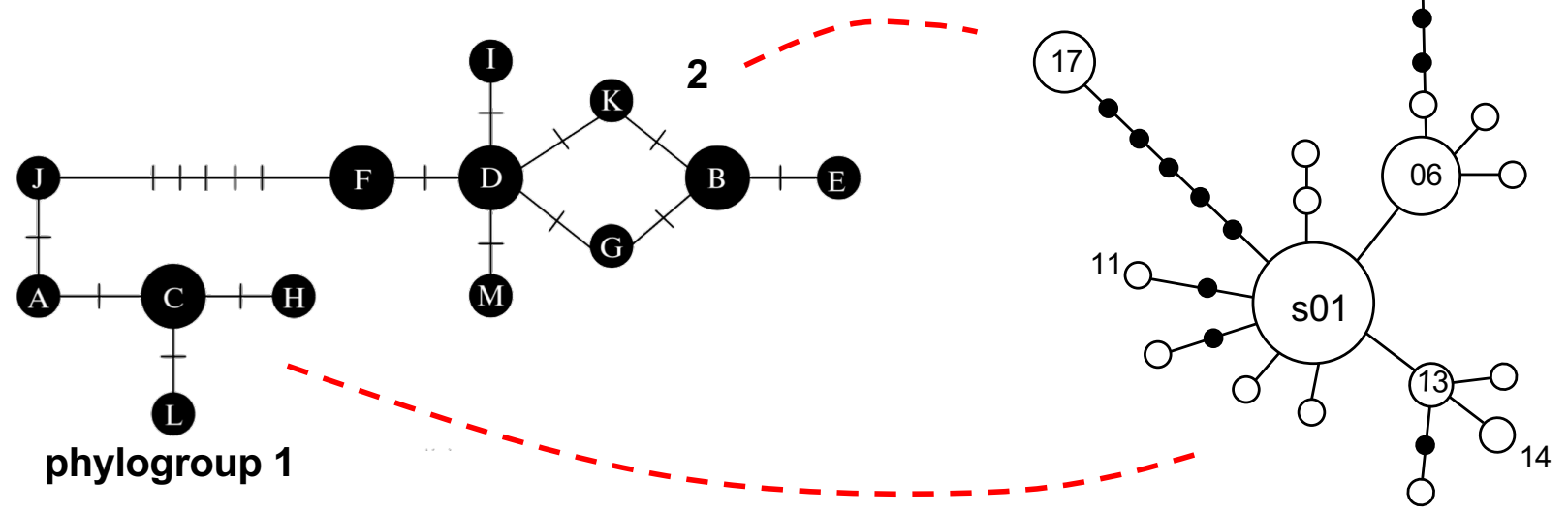

ESM Fig. S3 Possible correspondence (red broken lines) between the subgroups in the haplotype networks based on RFLP data in Brykov et al. (2013) (left) and those of cyt $b$ sequences by the present study (right), inferred from the distribution patterns and degrees of divergence. Numbers of hatches in connecting branches in left panels correspond to number of the nucleotide substitutions between haplotypes. See Figs. 5, 7 and 8 for the detailed explanation for the networks in right panels 